\title{
HBIM parametric modelling from clouds to perform structural analyses based on finite elements: a case study on a parabolic concrete vault
}

\author{
Emilio Abbate $^{1} \cdot$ Stefano Invernizzi $^{2}$ (D) $\cdot$ Antonia Spanò $^{1}$ (D)
}

Received: 8 April 2020 / Accepted: 23 September 2020/ Published online: 8 October 2020

(C) The Author(s) 2020

\begin{abstract}
The paper investigates the issue of finite element model development for the structural assessment of existing structures on the basis of detailed (terrestrial laser scanning and image-based) point clouds to parametric models generated using HBIM (Heritage Building Information Modelling) technology. Different procedures and software combinations are investigated in order to provide useful hints trying to solve some of the criticalities which are still unsolved albeit the subject has been under investigation since some years now. It is worth noting that, when assets belonging to the cultural heritage domain $(\mathrm{CH})$ are considered, the difficulties increase because of the peculiarity of the structural behaviour and often the singularity of the geometrical shape. The proposed methodology is presented considering the case of the "Paraboloide" of Casale (Italy), a construction from the early reinforced concrete age, which is now a relevant example of Italian concrete industrial heritage mainly due to the thin parabolic vault and the construction methodology that was so innovative for its time.
\end{abstract}

Keywords LiDAR clouds · HBIM · Structural assessment · Finite element modelling $\cdot$ FEM

\section{Introduction}

In the field of 3D modelling derived from survey systems that combine image-based (typically photogrammetric) and rangebased (laser scanning) techniques, the effectiveness of multiscale and multisensor approaches to meet different needs in terms of accuracy of metric and radiometric information of the point model, as well as density of the information content itself, is now proven (Murtiyoso et al. 2018; Munumer and Lerma 2015).

\section{Antonia Spanò}

antonia.spano@polito.it

Emilio Abbate

emilio.abbate@polito.it

Stefano Invernizzi

stefano.invernizzi@polito.it

1 DAD - Architecture and Design Department, Polytechnic University of Turin, Viale Mattioli 39, 10125 Torino, Italy

2 DISEG - Department of Structural. Geotechnical and Building Engineering, Polytechnic University of Turin, Corso Duca degli Abruzzi 24, 10129 Torino, Italy
Surely, the 3D survey based on laser scanning (TLS) is by far the preferred one for static or structural analyses, or to investigate the deviations and geometric anomalies of the factories, when it is necessary to obtain descriptive models and further modelling products of the reality under investigation that present simultaneously great reliability in terms of accuracy, information density and independence from environmental conditions at the time of acquisition (Castellazzi et al. 2015; Korumaz et al. 2017; Georgopoulos et al. 2017; Radicioni et al. 2017; Lubowiecka et al. 2009).

Although it is not a rule, it is a widespread trend that to prepare topologically structured models to conduct a finite element (FE) structural analysis, a workflow that provides a step for the generation of BIM-based models to obtain an object-based model that contains both geometric and semantic information, is preferred (Dore et al. 2015; Barazzetti et al. 2015).

It is also true that in the last decade, rapid and continuous innovations in the field of digital photogrammetry, which has introduced image-matching algorithms and the principles of structure from motion (SfM) derived from computer vision to obtain greater effectiveness in terms of automation, processing speed and quality of $3 \mathrm{D}$ results, have revolutionized the 
prospects of low-cost documentation of the built heritage, constituting an alternative solution to TLS.

This led to consider the 3D survey strategy to be less influential and to emphasize, after handling a point model, the semantic definition of the model offered by BIM approach (Volk et al. 2014), that is, the utility of being able to rely on object-based models, which encapsulate both the geometric characteristics of the buildings and the inherent semantic ones (Quattrini et al. 2015), above all the materials but also construction systems and state of conservation.

Starting from the first introduction ((Murphy et al. 2009) the concept of HBIM has developed around the paradigm of modelling historical structures using parametric objects contained in a database library. It is precisely from this objective that over the years developed the objective of using the reverse engineering principle to create automatically or semiautomatically from point models generated by reality-based techniques, models enriched by the semantic point of life (Murphy et al. 2012).

In the context of HBIM modelling, among the most shared concepts that oversee the generation process of numerical model for structural evaluations from point models to a BIM-based model, there is certainly the need to take into account both the geometry and the structural characterization of the built heritage elements, hence their spatial, topological and semantic relationships (Barazzetti et al. 2015; Logothetis et al. 2015).

The discretization process from reality to model is related to the aforementioned basic choices, which in the context of HBIM approaches proves to be particularly more complex than the scenario of new buildings that characterize the AEC world (Del Giudice and Osello 2013). This manuscript focuses on this in particular, deepening in the final phase also on the different configurations of the final model for the FEA analysis (finite element analysis).

Another particularly debated theme in the user community is certainly the issue of software compatibility and interoperability. The BIM approach is based on the IFC (Industry Foundation Classes) standard proposed by the International Alliance for Interoperability (IAI), now renamed Building Smart (National Institute Of Building Science, 2015); this standard gradually becomes more interoperable with the other modelling software tools (Logothetis et al. 2015), which must necessarily be considered for completing the process of geometries generation useful for the static and dynamic analyses that characterize the structural assessments. There are also proposals for the development of open tools in this sector too (Diara and Rinaudo 2018).

The deepened issues related to the level of development (LoD) (Lo Turco et al. 2016) and degree of generation (GoG) are also very relevant in the scenario of the complex architectures that distinguish the built heritage (Banfi 2017). Here, as it will be seen, the identification of the structural elements and the sensitivity necessary to identify numerical models faithful to the shape of the elements and to structural behaviour is certainly more relevant.

Referring to "Automatic and semi-automatic methods selection" the links to the different methods and different procedural strategies in use and which will be adopted in this study, known mainly as as-built, we still dwell on some particularly interesting and recently proposed reflections.

Starting from the assumption that the reality-based techniques of 3D survey have contributed to the definition of the geometry of objects and that ontologies are useful for the management of knowledge, Yang et al. (2019) propose a combined use of these technologies. Specifically, the HBIM model is converted into an ontological model to enrich semantic content. Obviously, these experiments are interesting for increasingly directing the collection and analysis of the $\mathrm{CH}$ towards a standardized knowledge and therefore easily shared by the many stakeholders who contribute to the conservation of the heritage (Acierno et al. 2017).

The research presented in this paper is focused on development of a workflow based on automatic/semi-automatic procedures able to detect surfaces and support the BIM modelling of parametric elements - with geometrical and semantic information data-from 3D survey collection. After the presentation of the methodology in the following section, the managing interpolation algorithm tools needed to achieve the surfaces and elements detection, even if characterized by complex shapes, are described and applied to the present case study. Moreover, the present work focuses on some structural analysis results of case study. In addition to the assessment of interoperability among parametric software and structural analysis software, a comparative finite element analysis is performed, considering three different configurations (3D, 2D, 1D). Linear static analysis and dynamic analysis, carried out according to the national standards, have been addressed and assessed in order to emphasize analogies and differences, as well as advantages and drawbacks, among the three possible adopted strategies.

\section{Automatic and semi-automatic methods selection}

The consolidated strategy identified to generate an as-built BIM and HBIM model is that which involves three tasks: the modelling of the shape, the recognition of the object and the identification of the relationships between the objects. Chiabrando et al. (2016) provided a very clear and concise summary of the modalities available for modelling the shape. These can both be applied to point clouds or triangulated mesh: model volumes and shaped from scratch (manual), fitting primitives to the point clouds (semi-automatic) and make cross sections and surface extrusion (semi-automatic).

Despite the spread of the aforementioned practices (Quattrini et al. 2015; Volk et al. 2014), the greatest attention is paid to 
automatic methods, which solve the capture of reality-based information by the so-called reverse engineering approach.

Thomson and Boehm (2015) report that both the geomatics and computer vision communities with the aim to achieve the reconstruction of building elements have focused "computational geometry algorithms to extract the $3 \mathrm{D}$ representation of building elements through segmentation, including surface normal approaches, plane sweeping, and region growing”. In this scenario, many studies aim to improve the effectiveness of the algorithms by testing improvements with the use of code (Leoni et al. 2019), or by customizing or verifying the effectiveness of the algorithms implemented in use, both linked in commercial or open software and evaluating their advantages and limits (Wang et al. 2015).

In the application that will be presented in this contribution, we have identified two appropriate methods by selecting in advance the structural elements characterized by a simple shape and those with a complex shape (Abbate 2016). For the first, the parametric HBIM model was generated following the automatic approach, while for the complex shape elements, we followed the strategy of obtaining NURBS surfaces from mesh or from vector profile of the elements.

Figure 1 depicts the streamline chart of adopted tasks.

Concerning software tools elected for the automatic reconstruction of geometries, after testing ScanToBIM (Imaginit), our choice was confirmed on the Edgewise module by ClearEdge3D. Edgewise Building. This tool is able to classify point clouds into surfaces that share coplanar points, aided by the operator picking elements on the cloud in order to add constrains to the surface searching. Once detected, the geometries can be imported into Revit environment in order to generate the parametric object-based geometry (Thomson and Boehm 2015).

The preliminary phase of a structural analysis, common to any chosen analytical approach, consists in simplifying the geometry of the structure through a numerical model capable for simulating in a realistic way the behaviour of the structure and the materials of which it is composed.

The three configurations representing different numerical models for the final FEA processing phase coincide with different choice that is possible to adopt.

The first configuration (1D) provides the extrapolation of the analytical model directly from the three-dimensional model, within which the single structural element is transmitted to Simulation Mechanical tool (by Autodesk) in the form of a one-dimensional element. In this way, through modelling based on the identification of the cross section characterizing the element, theoretically, faster processing is guaranteed compared with the other two.

The second configuration (2D) involves a procedure based on the extraction of the two-dimensional shape characterizing the structural element. The model, consisting essentially of "shell" elements, represents a compromise between accuracy of results and speed of execution.

Finally, the third (3D) model, discretized in threedimensional elements, called "Brick", guarantees an almost perfect definition of the geometric model, also verifying the processing times that could increase disproportionately due to the excessive geometric accuracy.

\section{Identification and surveying of structural elements}

\section{Case study: the former clinker warehouse known as "Paraboloide" in Casale}

The former clinker warehouse of Casale Monferrato called Paraboloide (Santarella 1926) certainly plays an important role in the framework of Italian industrial heritage. The
Fig. 1 Dual methods adopted considering the first main division in simple shape structural elements (path above) and complex shape structural elements (path below)

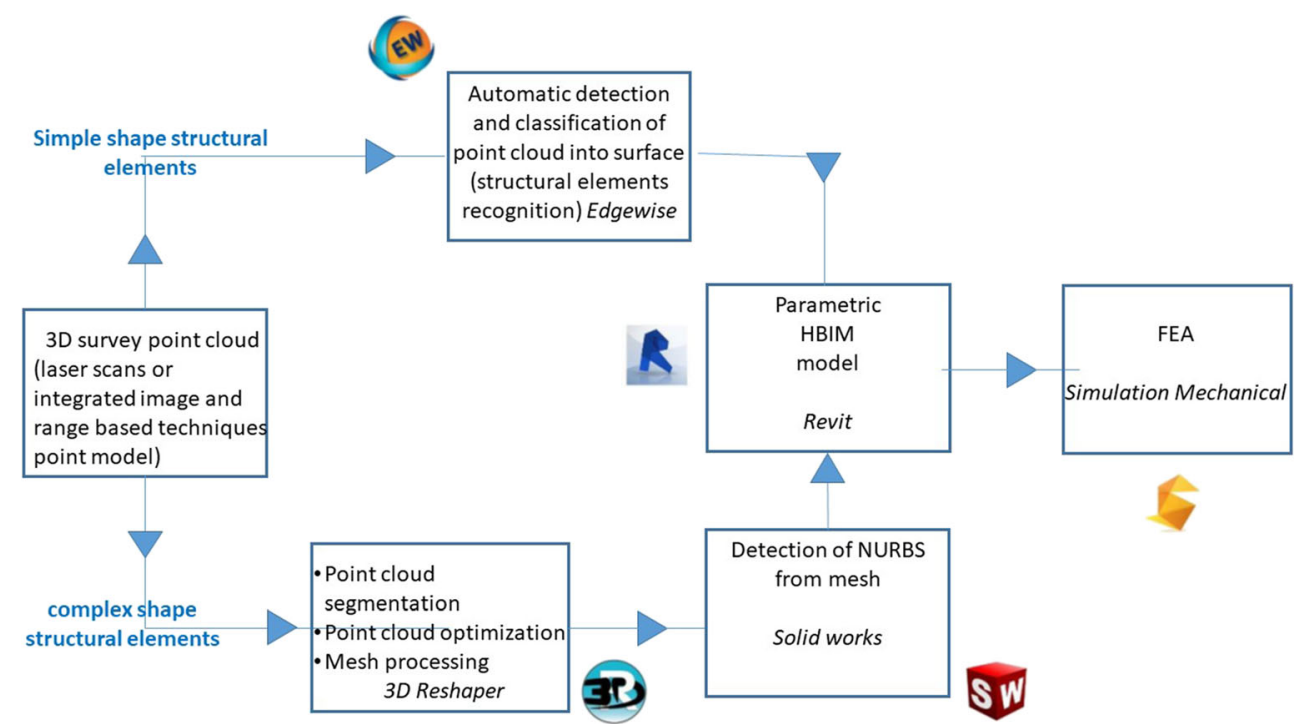


historical and constructive values consist mainly in the imposing thin vault, which presents likenesses with similarly shaped buildings designed by world-renowned engineers operating at the beginning of the twentieth century and conceiving new types of constructions using reinforced concrete. The studies on this structure have aimed at rebuilding an in-deep knowledge of the structure, ranging from the technological equipment to geometric characterization, structural organization of elements to overturn the condition of abandonment and reuse space as a cultural pole (Kitsaki 2011; Bertolini Cestari 2011).

The Paraboloide consists of an imposing parabolic section ribbed vault, entirely made of reinforced concrete, interspersed with eight rectangular section arches that guarantee rigidity to the entire structure. Thanks to the presence of these arches, inside it is possible to guarantee large spaces, necessary for carrying out material storage operations. As in other constructions of the same nature, the innovative shape of the paraboloid vault enhances the mechanical characteristics of the reinforced concrete, since with this solution the parabolic arches are subject to compression strains only.

The truss system resting on pillars with a rectangular section in the centre of the nave has been ascertained that are not original; it is an intervention achieved about 20 years later the first construction, created to obtain a raised floor necessary for the storage of timber. Nevertheless, they will still be taken into consideration in the structural evaluation of the construction.

The thickness of the thin vault is only $8 \mathrm{~cm}$, according to the potential offered by reinforced concrete that has inspired the conception of completely new resistant shapes and sections since the beginning of its diffusion.

Figure 2 shows the imposing building seen from outside, from a drone flight inside the extensive nave of the building, and other two picture show an underground corridor, before and after the removal of the encumbrance materials, which forced the 3D survey of the architectural complex to differ in two stages.

It is not so relevant for the results of this study, but it is useful to specify that the survey performed using TLS and photogrammetric techniques was performed in two different steps. This was determined since the need to deepen the studies on the state of health of the structure and consequently assess the seismic resistance capacity has evolved over time, as well as asbestos removal interventions in the basement level have been necessary, which have interdicted the usability of the structure for a period, not short indeed.

It is instead relevant for the purposes of the $3 \mathrm{D}$ metric survey to report that the usual approach that involves referring all the detailed $3 \mathrm{D}$ survey to the initial topographic control network allows dealing with the updates of the resulting model easily, as it does not change the reference system of the coordinates of the processed point clouds.

\section{D survey and point clouds generation}

The 3D survey of Paraboloide has been developed combining integrated laser scanning (TLS) and image-based method, using UAV (unmanned aerial vehicle) and close range photogrammetry to achieve a complete $3 \mathrm{D}$ point model of the building. As extensively highlighted in "Introduction", modern methods of accurate and three-dimensional data acquisition such as range-based (TLS) and image-based techniques are certainly more suitable than traditional ones for the metric documentation of complex sites and buildings with non-ordinary geometric primitives as the parabolic arch. The twodimensional architectural drawings have been also carried out since they are able to allow a deep geometric knowledge of elements concerning the whole building, contemporarily for basing the structural analysis and for sharing the achieved huge information with all involved stakeholder comprising the municipality owning the building.

The 3D survey was carried out in two successive stages, due to the unavailability of the basement floor cluttered with materials when it was first started (Fig. 2). It is an element of interest that the basement can currently be reached exclusively via ladders and is connected to the ground floor exclusively through the large hopper type openings for the aim of exchanging materials and to allow dust to escape from the underground floor and light to get inside. The latter was detected through the innovative MMS (mobile mapping system) consisting of a portable scanner and based on SLAM (simultaneous localization and mapping) technology, which in recent years has been added to the previous measurement systems to complete and integrate in a profitable way point clouds derived from other techniques (Eyre et al. 2016; Sammartano and Spanò 2018).

This section provides only the essential information concerning the 3D survey, mainly based on LiDAR (carried out in 2012), but effectively integrated above all by UAV photogrammetry (in 2017) for describing in a more accurately way the existing walkway at the top of the vault, which housed a track for sorting and mixing from above materials for the production of clinker. Point cloud from mobile scanner made it possible to complete the total description of the building, including the basement.

\section{- Topographical control network}

Precisely because of the need to carry out the survey in two stages (2012 and 2017), the topographic network has made it possible to provide spatial and temporal unity to the point clouds that have subsequently allowed to generate the parametric HBIM model. 
a

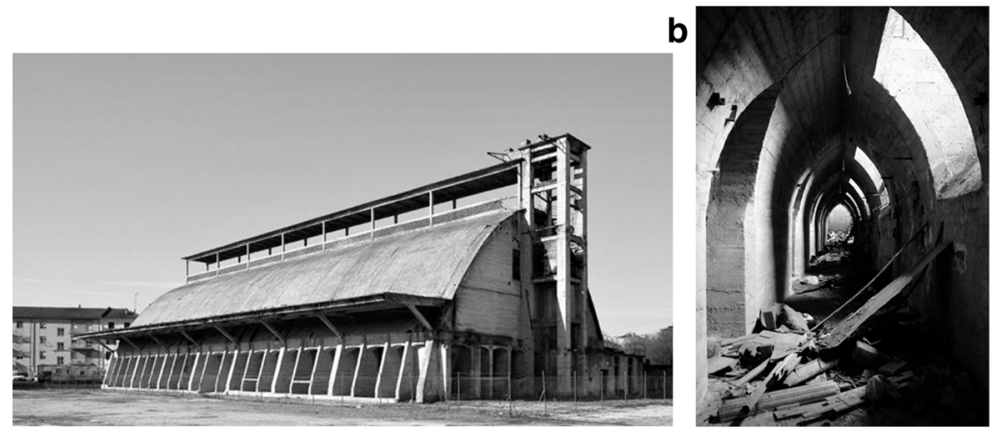

c
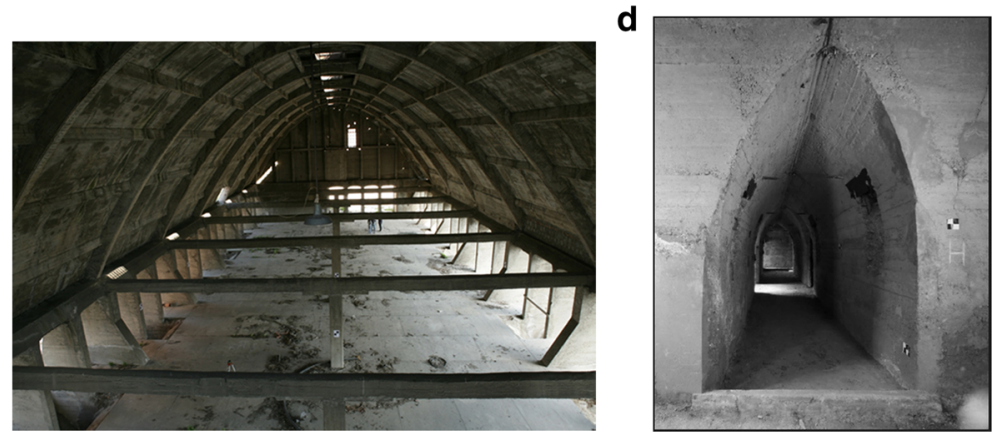

e

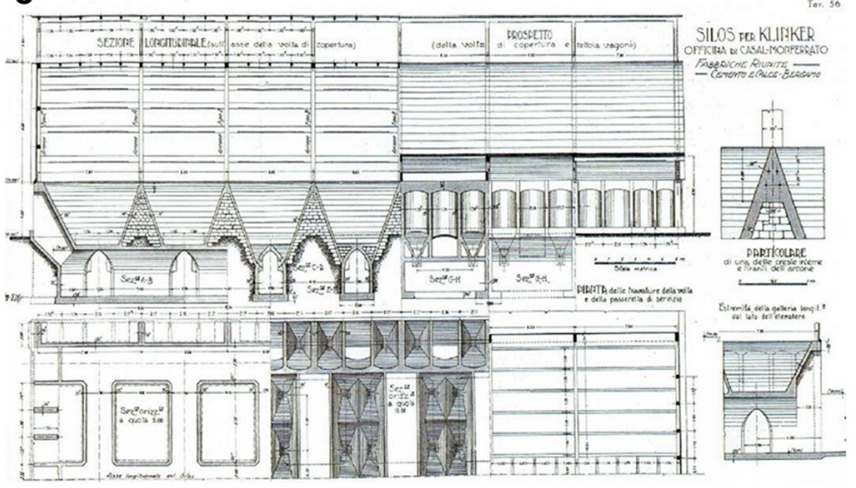

Fig. 2 The former clinker warehouse known as "Paraboloide" in Casale. (a) External view. (c) A view of the impressive space below the huge vault. (b, d) An underground corridor before and after the encumbrance

The topographic network, controlling error propagation, was planned for both phases by combining measurements with GNSS and traditional topographic techniques: at first the measurements with total station were adopted for the vertices inside the large vault of the structure (Fig. 3a), while for the second phase, new vertices were positioned using the GNSS technique at the entrance to the openings for the basement (Fig. 3b, c), and obviously the traditional technique was used in the basement floor.

The topographical network was calculated in both phases by adopting the reference system WGS84-ETRF2000 and using a permanent station coordinates; the calculation of the global coordinates was performed through the least squares compensation procedure; the coordinates average accuracy is of an usual order of magnitude for this type of survey and is shown in Table 1.

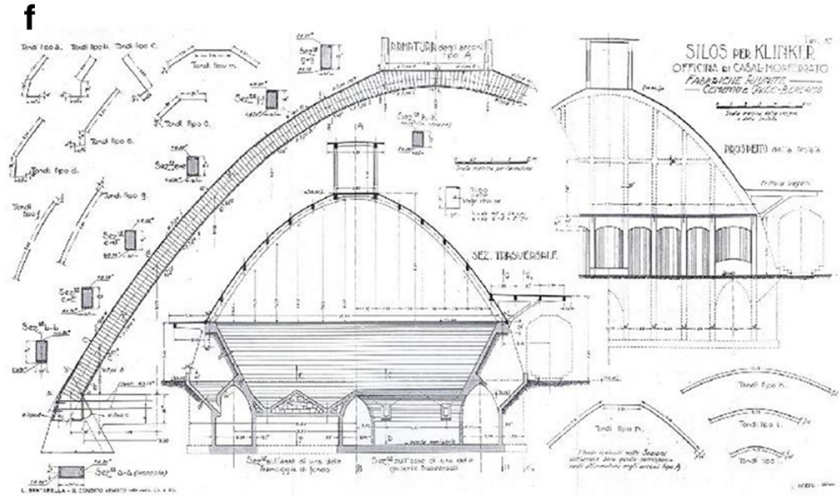

materials removal (involving asbestos that took time). (e, f) Technological equipment of the building in longitudinal and transversal sections from original design (Santarella 1926)

\section{- $\quad$ TLS survey}

According to the consolidated practice of traditional TLS acquisition (Luis et al. 2011) and scans registration, a several scan data were performed to cover the entire architectural context. N. 7 scan positions with the scanner placed on the ground guaranteed the coverage of the internal shape of the vault, obtaining the exact shape of the vault and ribs, but also the mapping of the regions affected by spalling of the concrete. The external shape of the building was acquired with a set of measuring observations from the ground, all around the building (11 scan positions), and exploiting an elevator (at an height ranging between 3.8 and $5.9 \mathrm{~m}$, corresponding to the height of the lateral roofing) to better acquire the above part of the vault and the shelters (12 scan positions). In the basement floor, a large number of scans have been also acquired ( 28 

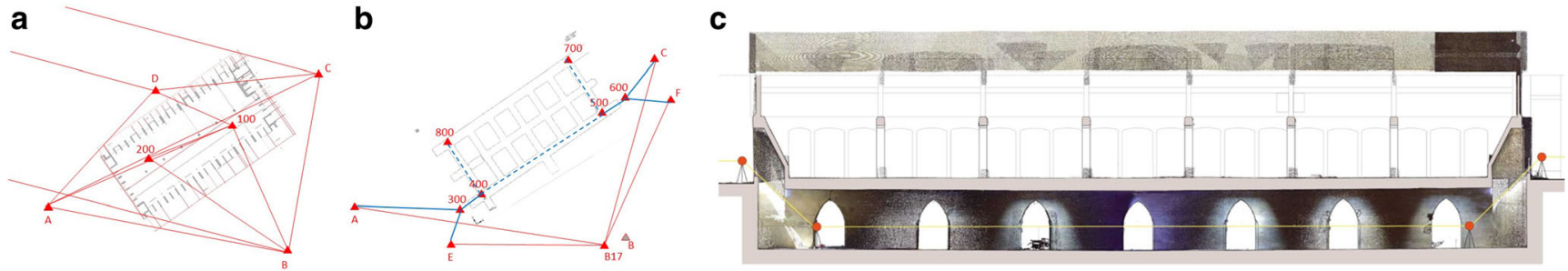

Fig. 3 Topographical control network of Paraboloide. (a) The first network for indoor and outdoor 3D survey. (b, c) The second network for the basement floor

scans) due to the morphology of the crossed corridors, but the LiDAR survey was mainly used to verify the scans performed through the mobile scanning system.

The FaroFocus ${ }^{3 \mathrm{D}}$ S120 (FARO Technologies, Inc., USA) acquired scans featured by a resolution of one point every $6 \mathrm{~mm}$ at $10 \mathrm{~m}$ (each scan has approximately 20 million points). A huge amount of materialized codified contrast markers and natural points from the scene, well distributed in the test area, were acquired by a total station (TS) in order to obtain a reliable network of control and check points. The average RMS error for all the scans registration resulted minor than $1 \mathrm{~cm}$ (about $83 \%$ points minus than $4 \mathrm{~mm}$ ).

\section{- UAV and DSLR photogrammetrical survey}

The Paraboloide and in particular its high portion has been covered by a low altitude photogrammetric flight performed by the Phantom 4 DJI multirotor drone, equipped with a 12 MP RGB camera (Fig. 4). The flight was carried out according to a scheme that provided for numerous adjacent swipes with an overlap between consecutive images of more than $90 \%$. The stereoscopic shots of the nadir and oblique imagery were acquired by setting the times of an image every couple of seconds and prefiguring a GSD (ground sampling distance) equal to $5 \mathrm{~mm}$.

In this case also, many control points were obviously engaged to achieve the BBA (bundle block adjustment) of images, obtained using the SfM technique according to the usual good practices in use (Chiabrando et al. 2019). Figure 5 and Table 2 show the most significant results of the survey based on aerial and close range photogrammetry (DSLR (digital single lens reflex) acquisition performed using Canon EOS 5DS $\mathrm{R}$ with a $24 \mathrm{~mm}$ lens) (Amadio 2017).

\section{- $\quad$ MMS survey}

The tunnels distributed in orthogonal grid in the basement, whose survey was carried out after the asbestos removal, are an environment in which the portable hand-held scanner Zeb Revo by GeoSLAM found a definitely suitable environment, despite the morphological regularity, to obtain an effective response from the SLAM algorithm. The maze of corridors has been used to obtain closed loop and a general round trip. The system composed by an Hokuyo 2D scanner and an inertial measurement unit (IMU) can take advantage in the processing guided from SLAM strategy of numerous roughness elements for the estimation of the trajectory and continuous cloud to cloud estimation of 3D scene reconstruction (Fig. 6). A couple of 10-min scans allowed to return the entire geometry of the basement, obtaining an overall drift of the scan attested on $2 \mathrm{~cm}$ (the result achieved though the comparison with the LiDAR cloud registered via control points).

- $2 \mathrm{D}$ architectural drawings (with vector and radiometric data integration)

\section{Cloud segmentation and structural elements recognition}

The observation of graphical metric results (Fig. 7) enables to assess a general good health conditions of the structure (except for material surfaces): there are no subsidence or anomalies of the large shape vault. Furthermore, the 3D model handling enables to know in detail the dimensional substance and the spatial order of each constructive element of the structure, so a schematic model illustrating the principal and secondary structural elements has been reconstructed with a high level of adherence to the real constructive arrangement (Invernizzi et al. 2019).
Table 1 Average root mean square errors for vertices coordinates

\begin{tabular}{llll}
\hline & Average RMSE x $[\mathrm{m}]$ & Average RMSE y [m] & Average RMSE z [m] \\
\hline GNSS vertices & 0.0039 & 0.0024 & 0.0079 \\
Total station vertices & 0.0095 & 0.0028 & 0.0036 \\
\hline
\end{tabular}




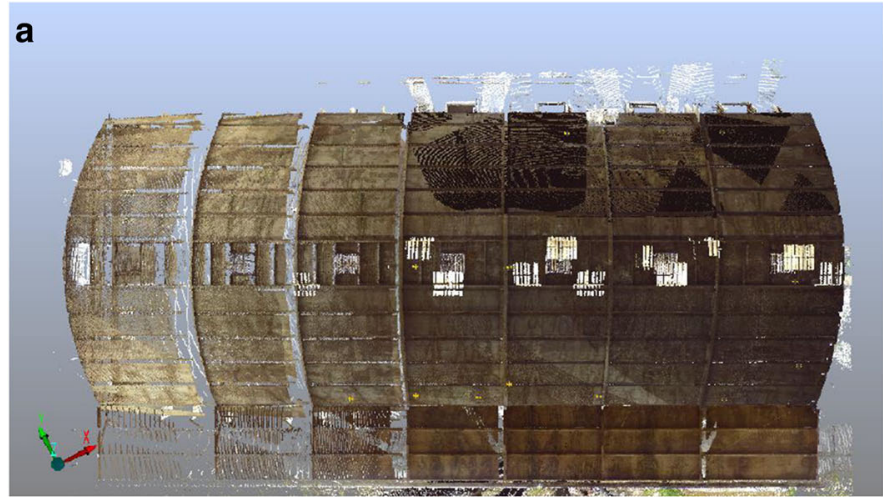

b

C
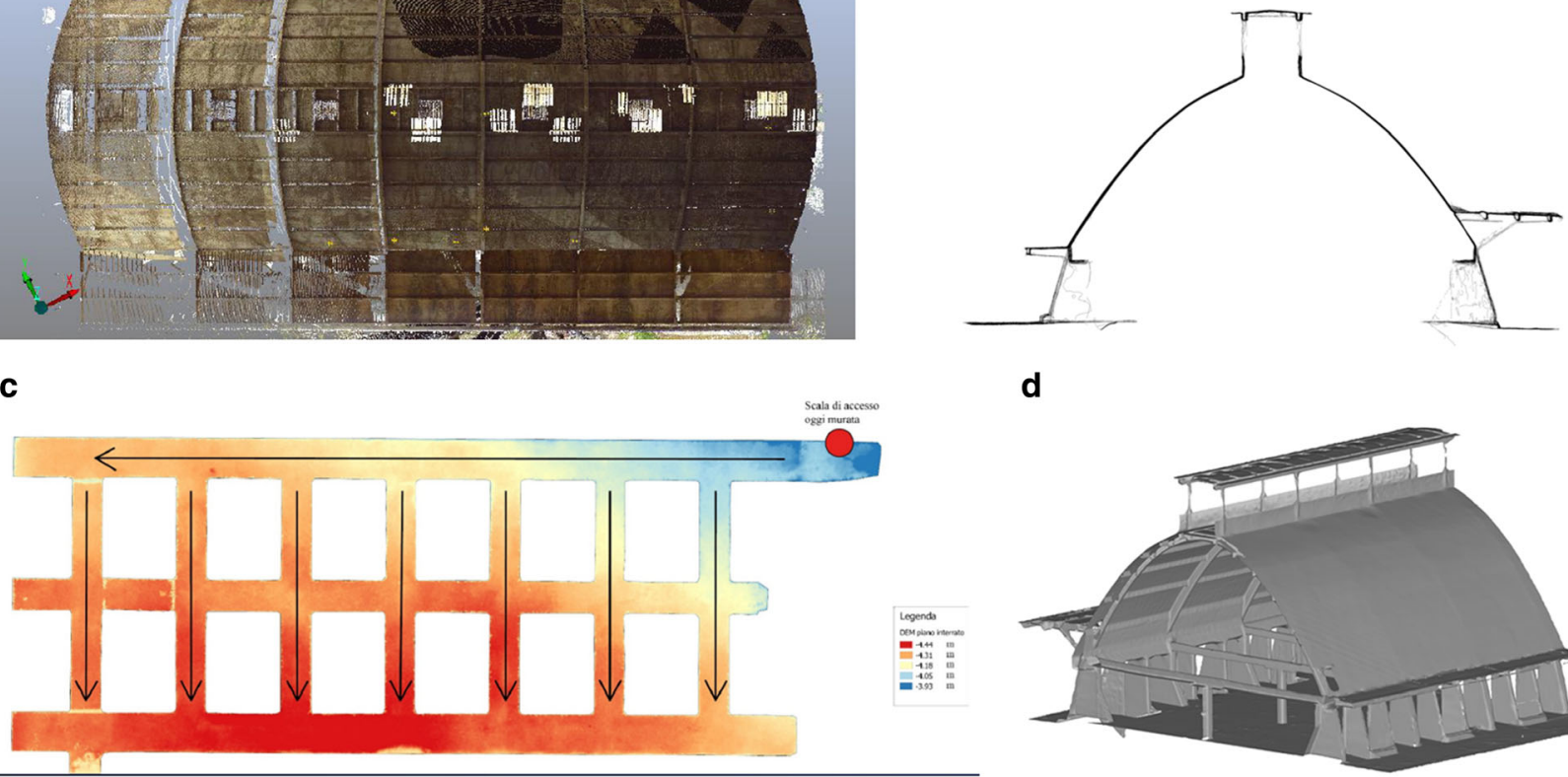

d

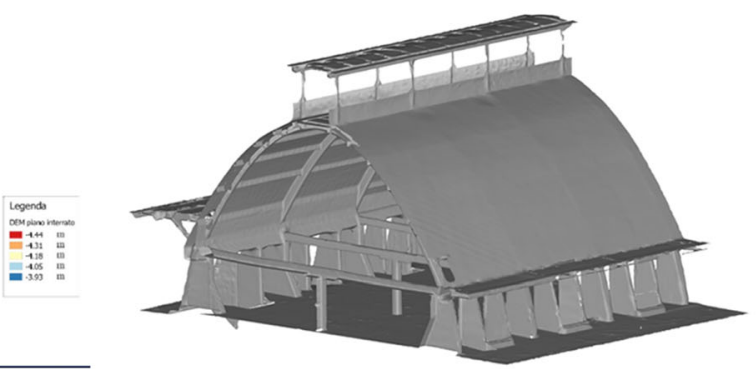

Fig. 4 Some 3D product from TLS survey: (a) a view of the intrados cloud, (b) a section profile showing the health conditions of the structure rather good, (c) a DSM of the basement floor shows the planned slope of

the flooring for the sliding of the rail carriages for the material transport and (d) a preliminary $3 \mathrm{D}$ mesh derived from the TLS survey

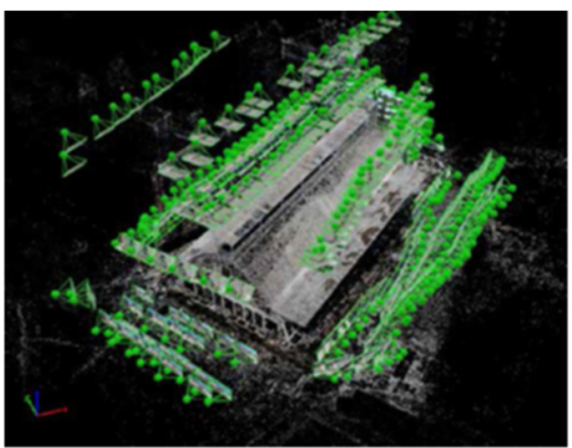

C

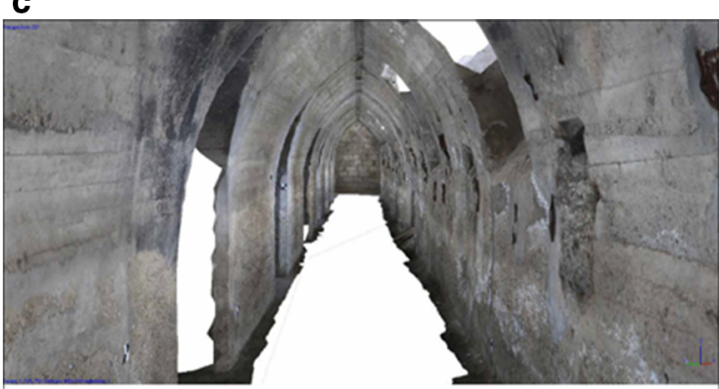

Fig. 5 Some results of photogrammetrical survey. (a) Sparse cloud with localization of projective centres during the drone flight (software Pix4D). (b) The dense cloud pertaining the Paraboloide (138 million points). (c) A textured image-based mesh of a longitudinal corridor of b

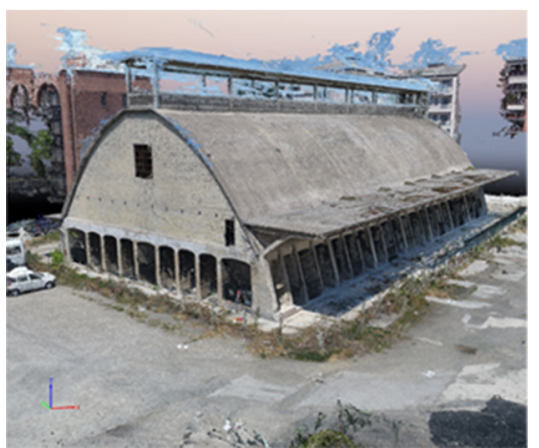

d

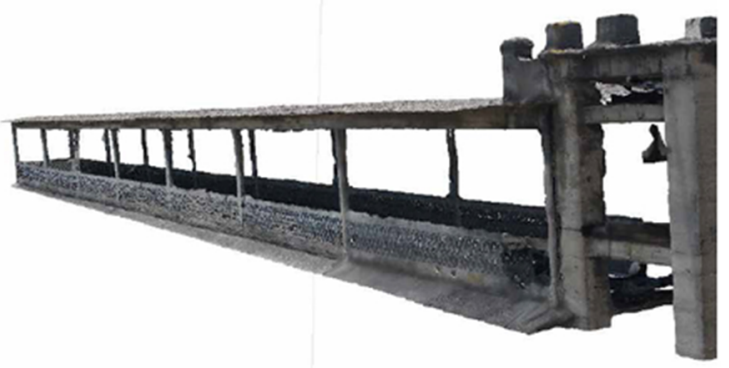

the basement floor (DSLR application). (d) The segmentation of the covered walkway positioned above the parabolic vault from the photogrammetrical mesh model (Amadio 2017) 
Table 2 UAV photogrammetric survey parameters and results

\begin{tabular}{llllll}
\hline $\begin{array}{l}\text { n. } \\
\text { images }\end{array}$ & $\begin{array}{l}\text { GSD } \\
{[\mathrm{m}]}\end{array}$ & $\begin{array}{l}\text { n. Check points-ground } \\
\text { control points }\end{array}$ & $\begin{array}{l}\text { Average } \\
\text { RMSE }[\mathrm{m}]\end{array}$ & $\begin{array}{l}\text { Average density } \\
{\left[\text { points } / \mathrm{m}^{3}\right]}\end{array}$ & $\begin{array}{l}\text { 3D dense cloud } \\
\text { (ml points) }\end{array}$ \\
\hline 374 & 0.0058 & 44 & 0.0090 & 5117 & 138 \\
\hline
\end{tabular}

The Paraboloide has a rectangular plan approximately $23 \times$ $53 \mathrm{~m}$ in size (involving the tower), covering a total area of about $1200 \mathrm{~m}^{2}$. The building develops for a height above ground of $16.10 \mathrm{~m}$, inside which there is the covered gallery positioned above the parabolic vault, with a height of $3.5 \mathrm{~m}$. The parabolic vault is characterized by a thickness of $8 \mathrm{~cm}$, which is interspersed with 8 transverse parabolic arches and 12 longitudinal beams with a rectangular section of different sizes.

The entire vaulted roof is supported by 48 trapezoidal-shaped perimeter pillars, among which 16 in correspondence with the parabolic arches, which have a different profile as well as a greater thickness to counteract the thrust deriving from the arch itself, assuming a counter-bearing function. The entire structure arises from the repetition of a single module that is repeated for the entire length of the building. Each single span is made up of two parabolic arches, inside which there are two buttressing pillars, with a thickness equal to $50 \mathrm{~cm}$, and two secondary pillars, half the thickness of the previous ones, which identify the connections to the basement.

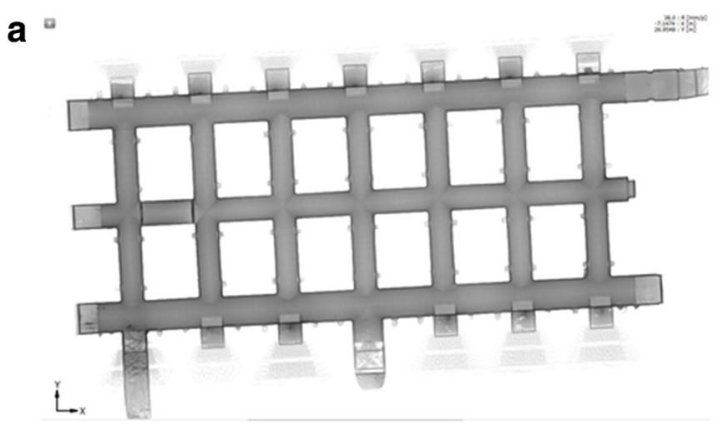

C

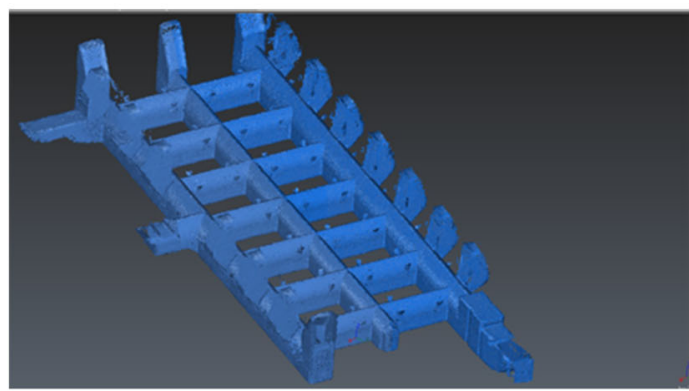

Fig. 6 MMS survey products. (a) 3D continuous cloud derived by Zeb Revo GeoSLAM portable scanner in a planimetric view. (b) Acquisition phase. (c) 3D mesh from low density scans obtained from MMS survey.
Even if a preliminary overall structural assessment has been achieved (Invernizzi et al. 2019) in the perspective of the present methodological study, we are going to show the identification of base structural elements pertaining a single span of the Paraboloide (Fig. 8).

\section{BIM modelling using clouds to BIM and meshes to BIM approach}

As mentioned in "Automatic and semi-automatic methods selection", the structural elements of the Paraboloide have been divided into two different categories: the first of structural elements featured by a simple shape, for which it was possible to apply an automatic method for basing geometric configuration of HBIM model ("Automatic recognition of regular shaped structural elements"). For complex structural elements instead, the semi-automatic procedure based on the calculation of NURBS profiles and surfaces has been adopted ("Semi-automatic modelling for complex shaped structural elements").

b

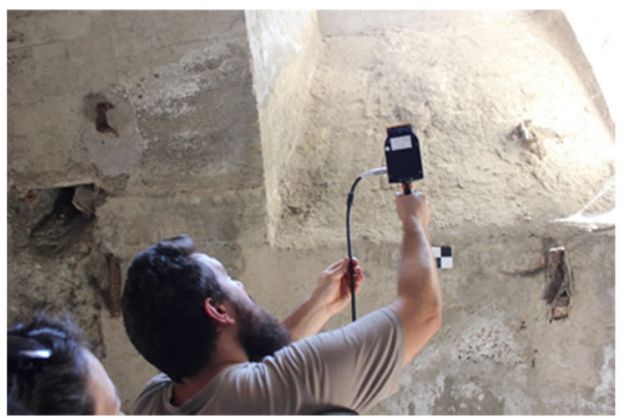

d

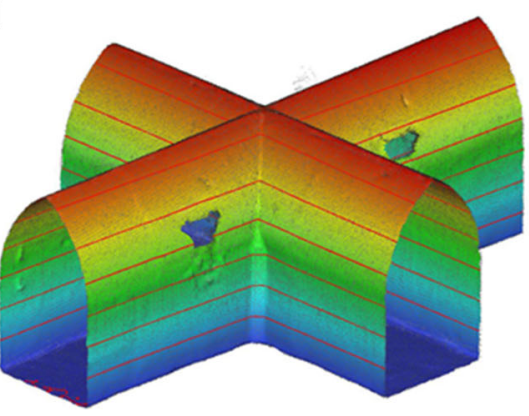

(d) A portion of the 3D point model coloured by levels and showing anomalies and roughness of masonries 


\section{Automatic recognition of regular shaped structural elements}

The Edgewise plug-in by Clearedge3D has a dedicated module for structural design that can count on a quantity of standardized objects in its database with which to compare the objects recognized in the point clouds. It enables to eliminate any inaccuracies that could arise from an imprecise manual modelling by the user, through the use of interpolating tools capable of identifying the structural elements completely automatically. So, in addition to drastically reducing the phase of generating the three-dimensional model extrapolated from the point cloud, it enables to create an automatic smart sheet where it is possible to collect information regarding materials and dimensions, and at the end, it guarantees direct transmission to Revit@, thus avoiding the need to remodel the element in a parametric environment.

From the non-structured point cloud, simple beams, secondary warping elements of the vault and pillars of the Paraboloide have been effectively modelled in this way, as Fig. 9 shows.
The Edgewise plug-in introduces a proprietary format capable of making scans easily manageable, converting them through the process scan command, into format .c3DB. The software is able to support various import formats, including the following: .c3s, .ptg, .tzf, .ptx, .ztf, .E57, .rsp, .pts, .dp and .fls; that means that clouds can be aligned and geo-referenced in a large number of different scan management software.

Once the modelling phase is completed, the user has the possibility to export the work in different formats, including Revit (.c3rvt), Leica (.coe), AutoCAD (.coe) and Microstation (.coe). Through the export to Revit command, the newly modelled elements will be imported into the parametric program, divided by categories and families with the related information regarding dimensions and materials.

\section{Semi-automatic modelling for complex shaped structural elements}

Certainly, the moulded buttress pillars of the historical structure being investigated in the present research, as well as the parabolic arches with variable section profiles, do not belong a

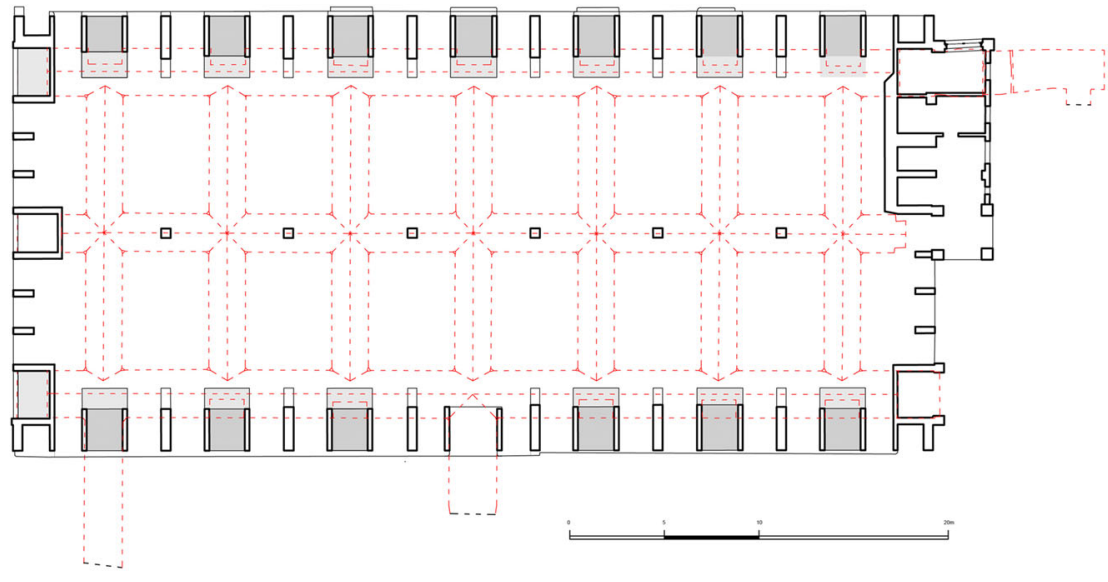

b

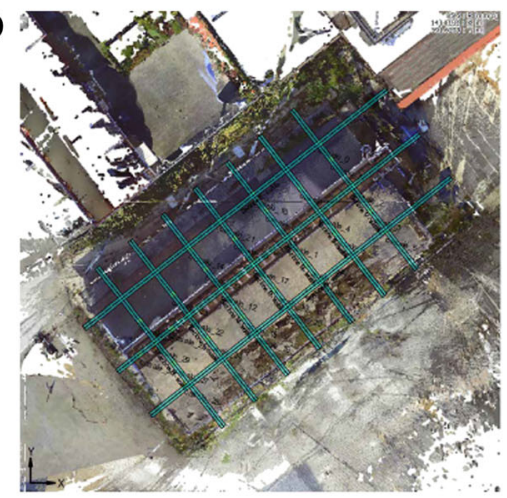

C

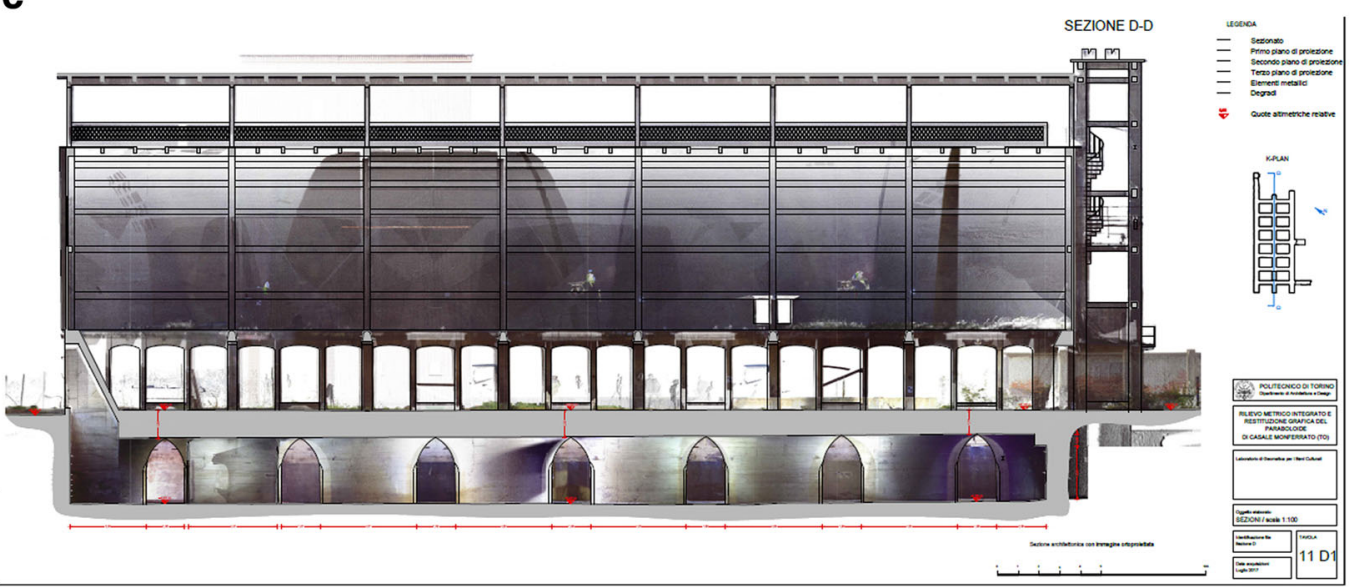

Fig. 7 2D architectural drawings. (a) Ground floor plan superimposed to hypogeum space in red. (b) A view of planned section upon the overall cloud, comprising different technique survey cloud and underground and above ground structures. (c) A longitudinal architectural section. (d) An example of transversal section 


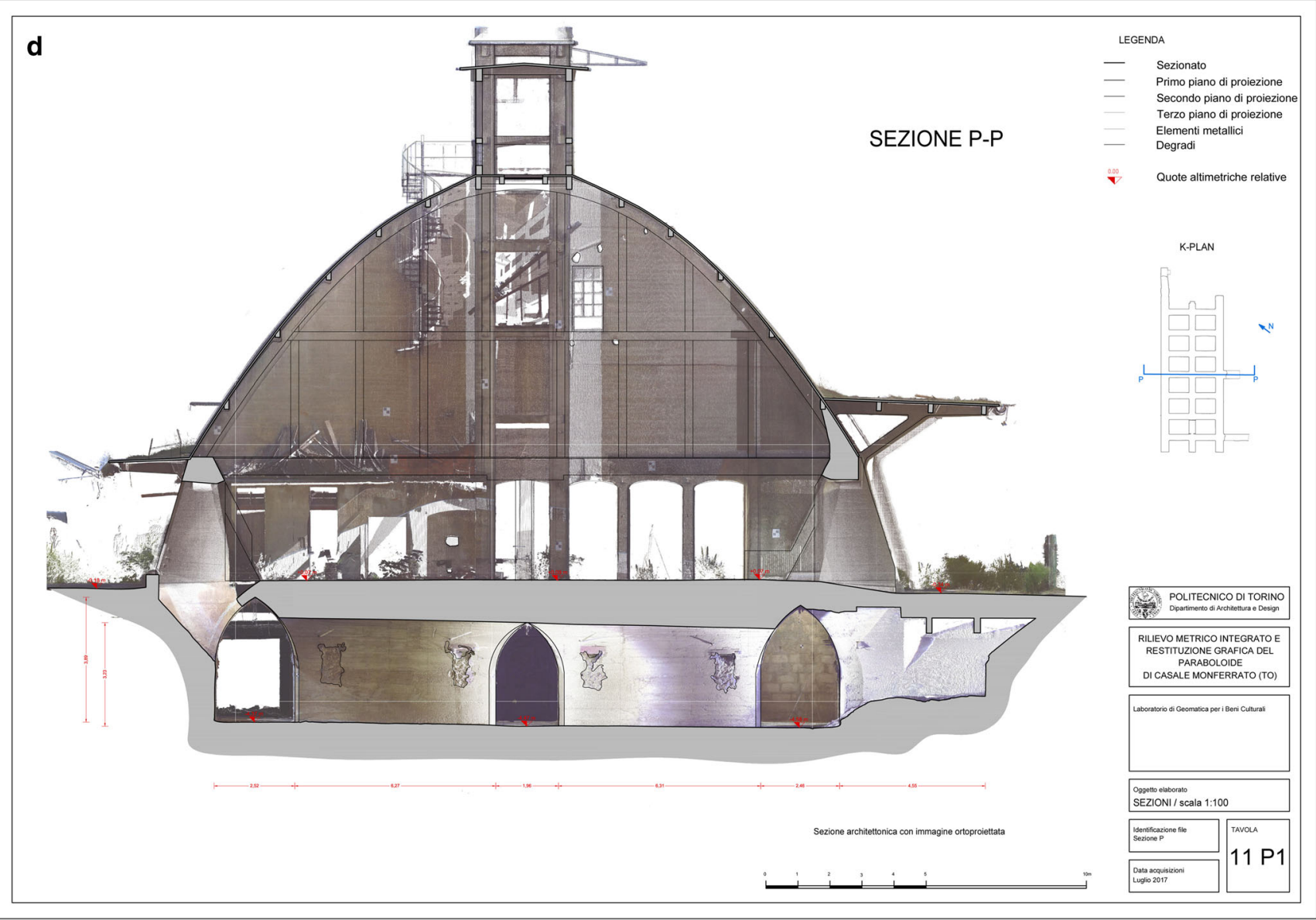

Fig. 7 (continued)

to the category of standardized elements, for which the use of the semi-automatic method was mandatory.

The tasks performed are organized as follows:

- Point cloud segmentation accordingly to the hierarchic structural elements recognition (using 3DReshaper® software), as presented in Fig. 8b.

- Optimization of the overall point cloud database using filtering and cleaning tools (3DReshaper®). In order to preserve the geometric characterization of the cloud, the value adopted for running the command keeping best points was $0.008 \mathrm{~m}$.

- Processing of the polygon MESH derived from point cloud, using the two-step triangulation command (3DReshaper@).

- Mesh editing and evaluation of the absence of topological errors such as holes in the surface (using 3DReshaper®); then mesh model export using the interoperable format .obj with the aim to run interpolating algorithm of structural elements using the suitable software Solidworks ${ }^{\circledR}$.

- Use of region growing algorithms for the detection of mathematical NURBS surface (non-uniform rational basis splines) from MESH (using Solidworks® software). Before moving on to parametric modelling, it was deemed necessary to check the correspondence between the mesh and the NURBS surface just created. In Solidworks, the deviation analysis was used, able to identify the minimum and maximum deviation between the two surfaces. In the present test of the structural elements of the Paraboloide, the maximum deviation identified is $1 \mathrm{~mm}$.

- Parameterization of NURBS surface into HBIM model (Revit@).

\section{HBIM model}

An important aspect that is worth to highlight concerns the structural elements modelled using automatic method: they are imported in Revit keeping the same spatial coordinates obtained from the laser scans. The same does not happen to the elements, which instead due to the complex shape originate by semi-automatic methods and must undergo a series of 

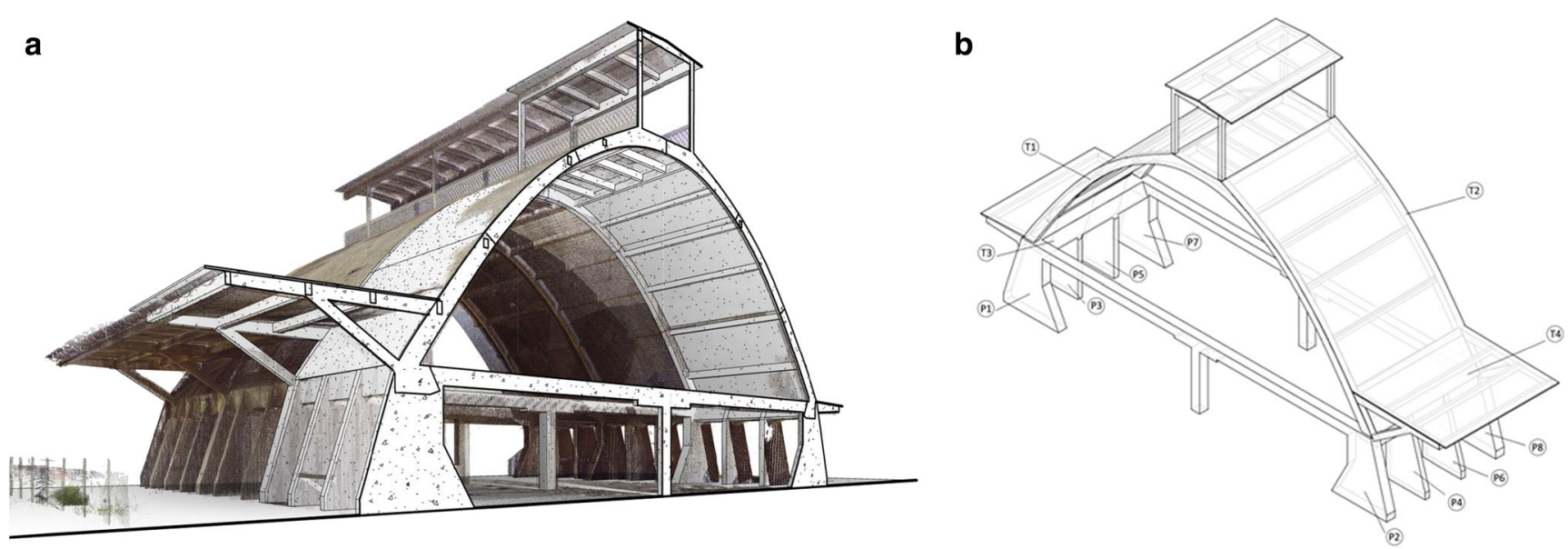

Fig. 8 Structural elements of the building. (a) An overall 3D model of the Paraboloide. (b) First study and categorization of the structural elements in a single span

procedural actions to constitute a correct HBIM model (structural elements families) (Fig. 10).

The complex shaped structural elements were imported into Revit through the .sat interchange format, paying particular attention to the measurement unit adopted in Solidworks.

After the import, a particularly important parameter is the number of dimensions to associate with the model, which is closely linked to the morphology of the element and the degree of complexity of the shapes. For instance, in the case of the buttress pillar, it was considered appropriate to associate the depth, the width, the internal height, the height of the base, the external width and the upper width so that a parametric element that can be modified in all its parts can be constituted:
The following Fig. 11 illustrates the result, with a brief indication of the information concerning classes, materials and construction phases that constitute the semantic contents to the parametric model.

\section{From BIM to FEM}

The integration between BIM system and FEM software is not always straightforward, although in principle the data should be exchangeable thanks to interoperability. In addition, the structural model to be analysed in the framework of finite element analysis (FEA) is not univocally defined, depending a

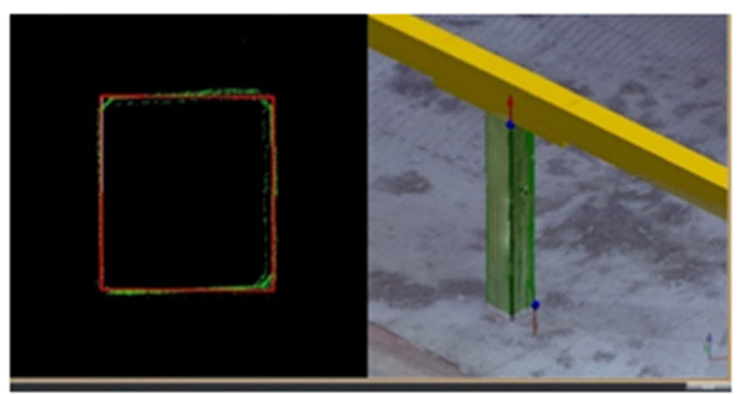

c

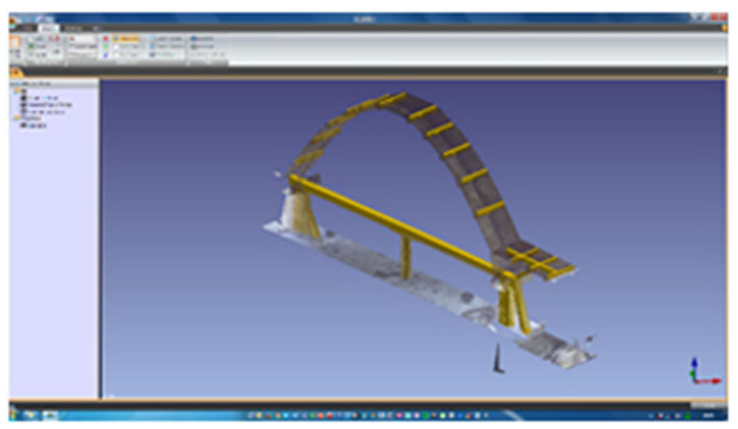

b

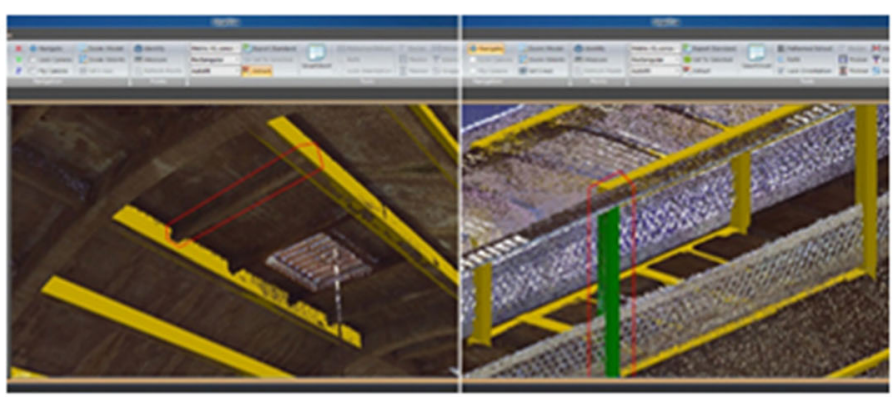

d

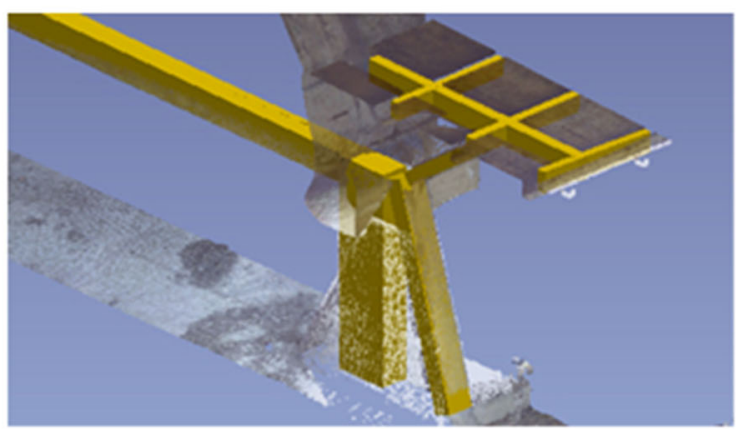

Fig. 9 Automatic recognition and modelling of regular shaped structural elements using Edgewise plug-in. (a, b) Standardized structural elements properly recognized and modelled. (c, d) In comparison with previous elements, irregular shaped elements are wrongly modelled 


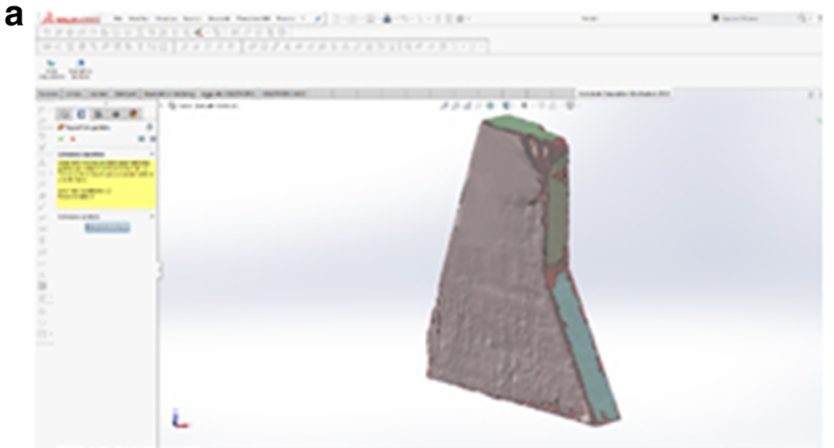

C

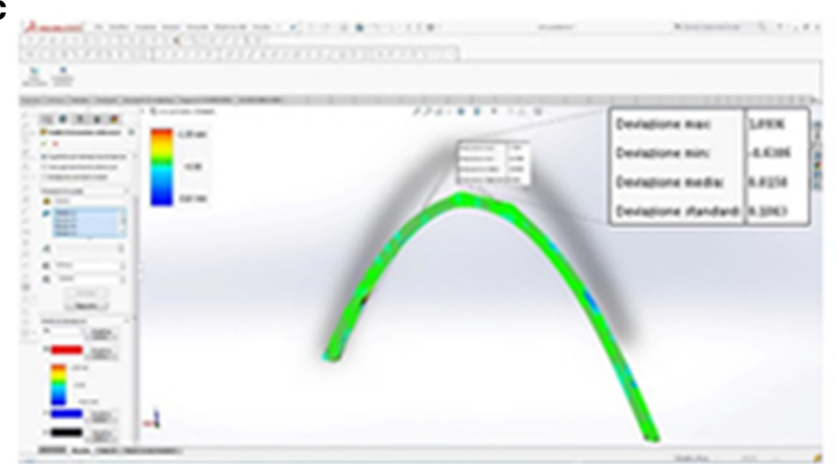

Fig. 10 Some steps of semi-automatic method applied. (a) The region growing algorithm recognizing surfaces on mesh model of the buttress pillar. (b) Deviation analysis performed among the NURBS surface and original mesh surface ( $\max$ deviation equal to $0.5 \mathrm{~mm}$ ). (c) Same

on a series of engineering assumption and simplifications. Taking into consideration the case study of the Paraboloide, different topological assumptions can be made, ranging from fully three-dimensional modelling to reduced onedimensional beam frame, including bi-dimensional shell models. In addition, different reduced structural elements can be combined together, provided that correct tyings and compatibility are guaranteed.

In the present section, some aspects of the procedure are described, first considering isolated structural elements and then taking into consideration a complete section of the whole structure.

\section{The main buttress pillar}

The main buttress pillars are placed in correspondence of the great arches, in order to sustain both the vertical loads and the horizontal thrust from the main arches. Their geometry is characterized by a constant thickness, which is smaller than the other two dimensions, and a variable cross section. They could be modelled as three-dimensional bodies, as well as constant thickness shells or as inclined pillars with variable cross section.

We exploited all the three different possibilities. From the point of view of correct interoperability, working in the frameworks of the Autodesk suite, no particular problems arise. b

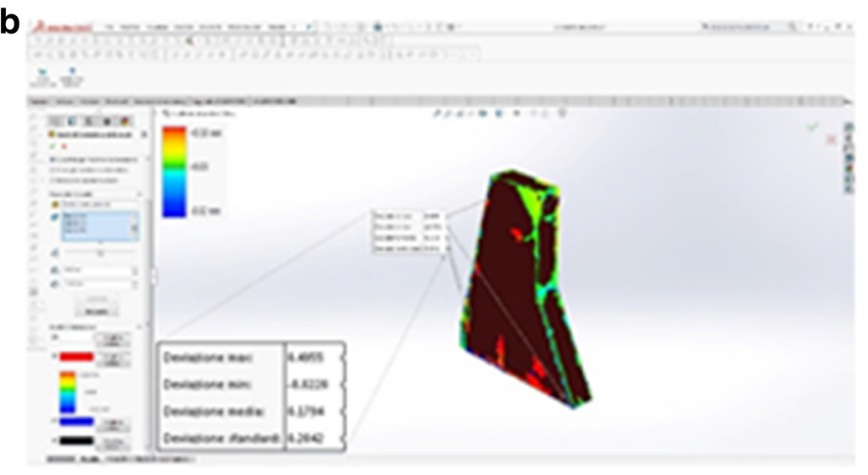

d

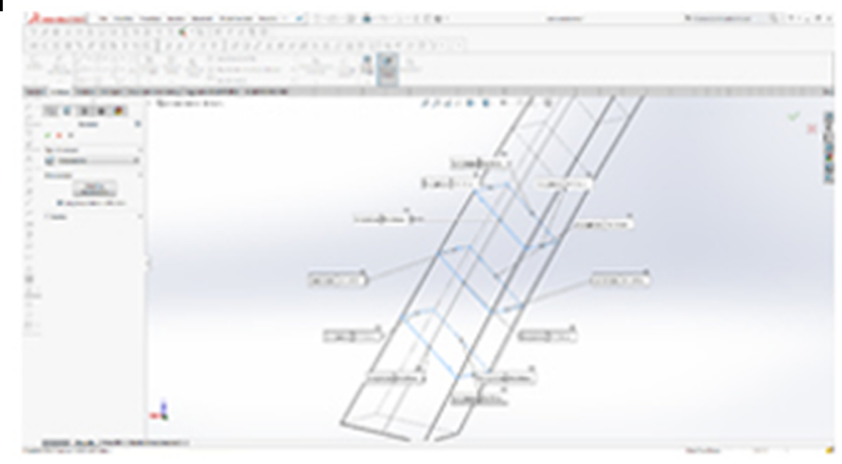

deviation analysis performed on the parabolic arch (max deviation equal to $1 \mathrm{~mm}$ ). (d) Automatic parametrization of section profiles on planes perpendicular to the axis of the arch to optimize the parametric handling of arch model

Importing the volumes is straightforward, and the mesh generation is effective. The shell model can be obtained from body geometry exploiting the mean plane function, in an automatic way. The one-dimensional model requires some more work; in fact, the variability of cross section must be discretized, and variable eccentricity must be provided in addition to the cross sections (Fig. 12).

Analogous boundary conditions must be prescribed differently based on the finite element number and typology of degree of freedom; therefore, reduced models usually require fixed rotations in addition to fixed displacements (Fig. 13).

It is worth noting that the mechanical properties of the structural elements can be derived from the material property of the BIM model, taking advance of precompiled conversion tables, which are capable to provide the necessary elastic modulus and the Poisson coefficient.

A simple comparison has been carried out among the three models, considering the effect of dead load. In Fig. 14, the contour plot of equivalent von Mises stress is depicted. It is possible to observe that the mean stress is assessed in very similar way by the different models. On the other hand, the stress concentration in correspondence of the main cross section discontinuity cannot be described by the oversimplified 1D model (Fig. 14). 
Edge beam

Class: structural

frame

Material:

reinforced

concrete

Volume: $4.6 \mathrm{~m}^{3}$

Construction

Vault rib

Class: structural

pillar

Material:

reinforced

concrete

Volume: $0.2 \mathrm{~m}^{3}$

Construction

phase: original

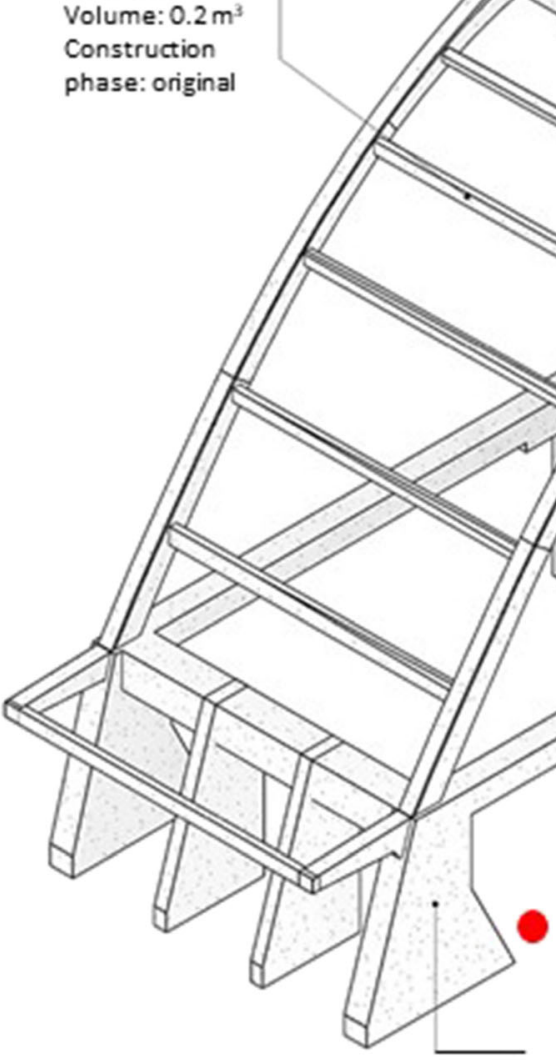

Buttress pillar

Class: structural

pillar

Material:

reinforced

concrete

Volume: $4 \mathrm{~m}^{3}$

Construction

phase: original phase: original

Fig. 11 Result of the complete HBIM model of the span, with semantic information regarding the database objects

As a result, the combination of Revit and Simulation Mechanical can be suggested due to the best compatibility and performance.

\section{Comparative FEM analysis}

Based on the experience carried out on the single structural element, the procedure has been applied to a whole section of the Paraboloide. Despite the complexity of the geometry, with intersection of several parts with very general shape, the procedure worked smoothly.
The algorithm for detection of the element axis, as well as of the mean plane for shell macro elements, was successful even in correspondence of complex joints. The parametrized geometry was correctly imported from Revit regardless the chosen dimensionality for the finite element discretization.

The obtained finite element models were assessed comparing the structural response accounting for static loads and the modal response in terms of eigen-frequencies and eigenshapes.

It is worth noting that, in order to account for the in-plane stiffness of the Paraboloide thin shell vault in the 1D structural model, equivalent diagonal elements have been introduced according to Hrennikoff (1949). This improvement can be 
a

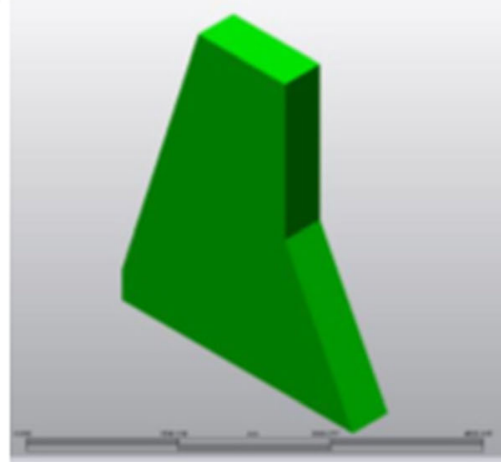

C

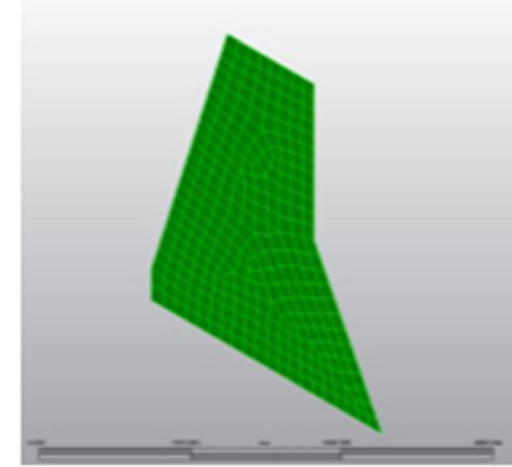

b

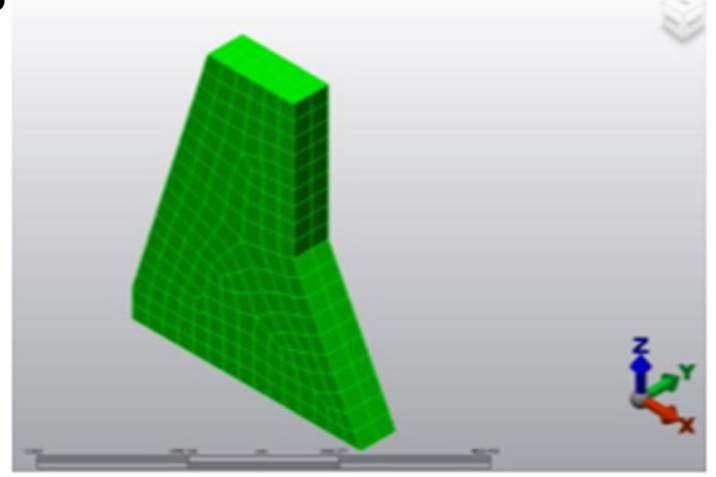

d

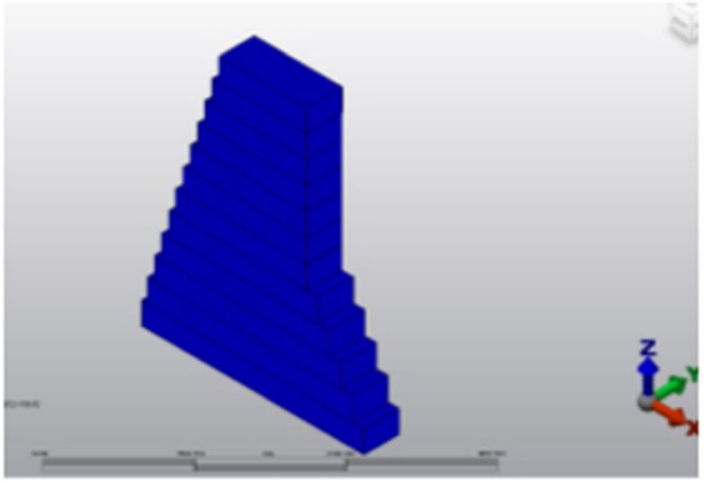

Fig. 12 (a) Solid geometry as imported from the BIM model. (b) 3D brick element mesh. (c) 2D shell element mesh. (d) Solid representation of the 1D beam with variable cross section discretization

a

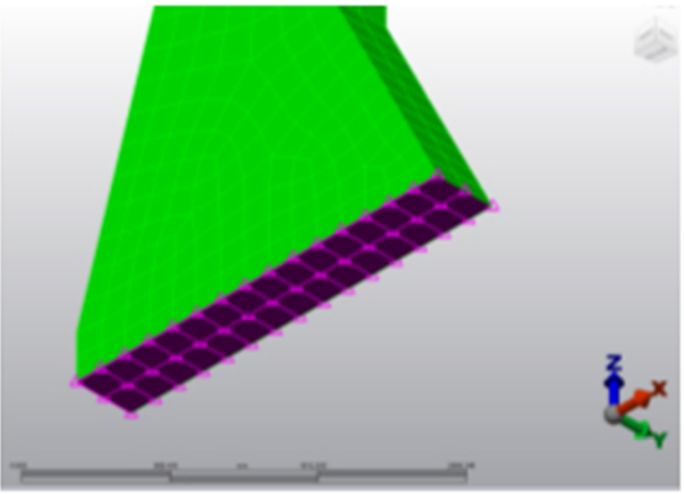

C

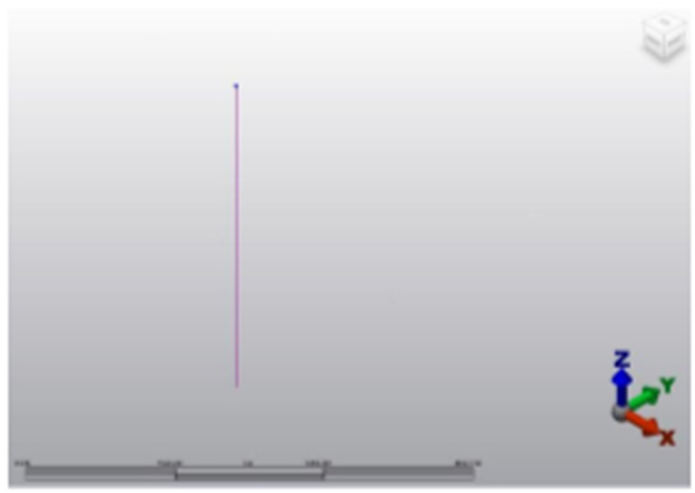

b

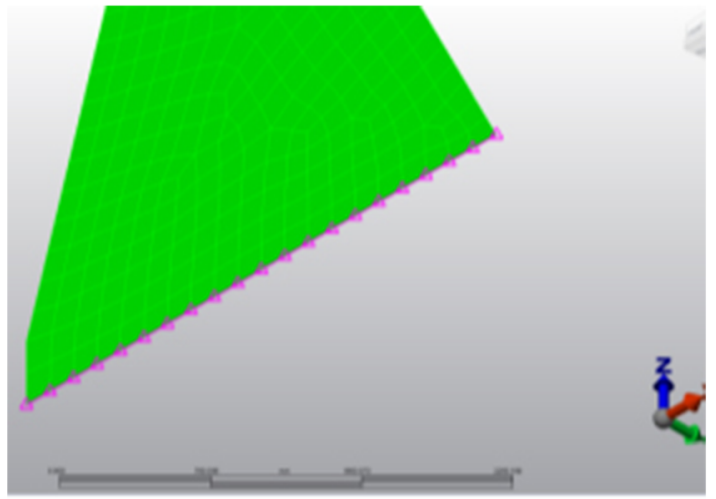

d

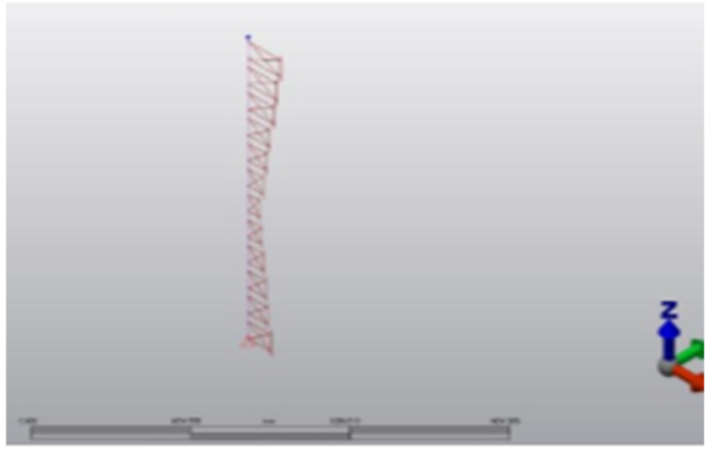

Fig. 13 (a) Boundary conditions assigned for 3D solid elements and (b) 2D shell elements. (c) 1D beam element and (d) variable eccentricity scheme 

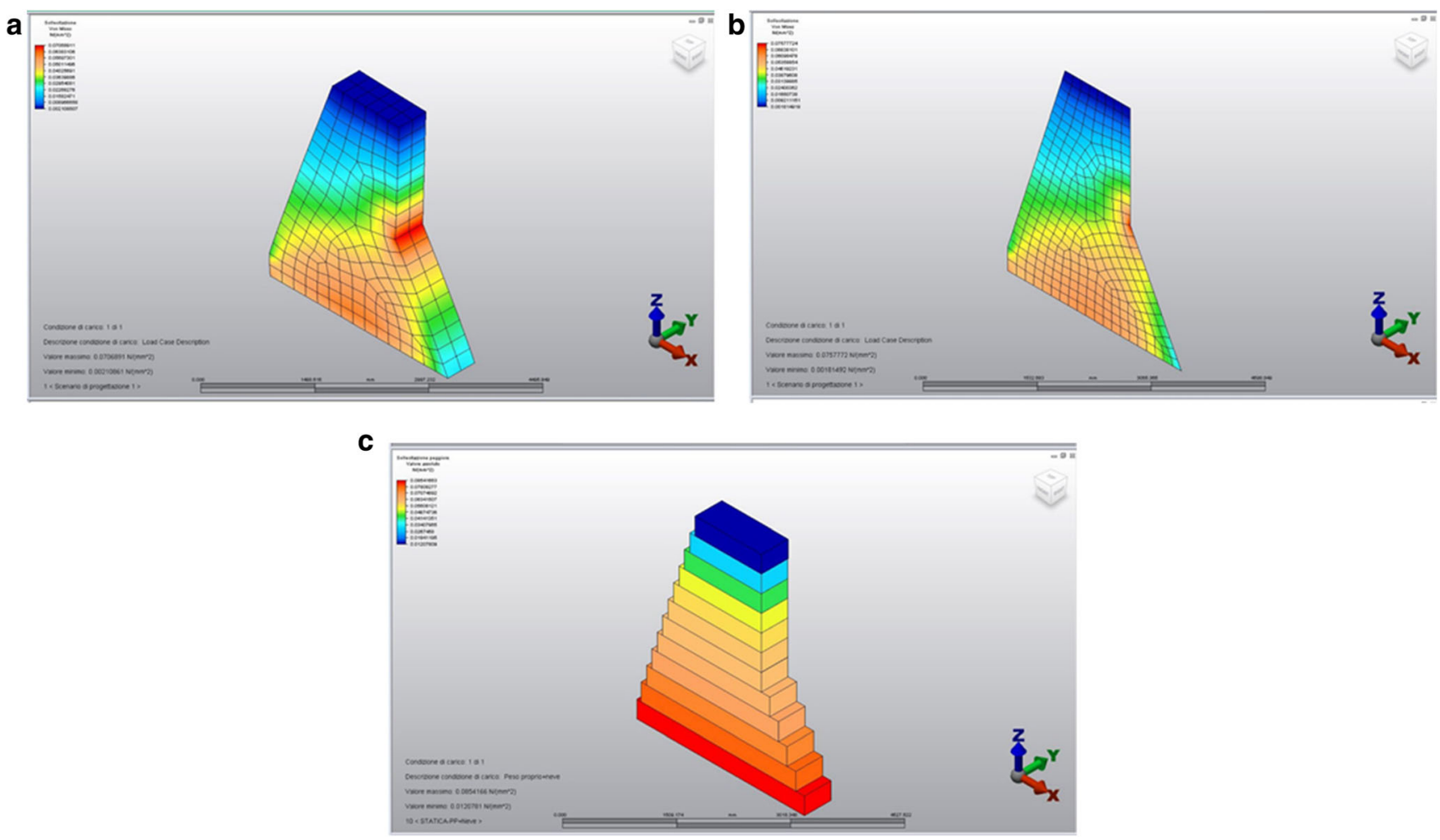

Fig. 14 Equivalent von Mises stress of the main buttress pillar under the effect of self-weight

disregarded if only vertical loading is considered but become essential for a correct assessment of the dynamic behaviour in terms of eigen-frequencies and eigen-shapes.

The magnitude of the equivalent von Mises stress is contoured, for the three models in Fig. 15. The values compare well, although local maximum stress, which depends on local behaviour, are smoothed out in reduced models. Therefore, the higher dimensional models provide higher local values. The displacements are also comparable, as shown in Fig. 16. The first modal shape for each model is reported in Fig. 17.

\section{Interoperability and HBIM}

The test carried out has confirmed that structuring an HBIM model starting from point clouds of photogrammetric origin or generated from TLS technique to direct the study towards the FEA analysis is certainly a possible objective and above all particularly interesting in order to manage the structural elements of a building in parametric form. The presence of standardized structural elements makes the process certainly easy and free of particular interoperability problems among the software used. The presence instead of structural elements of complex shape introduces the need for a further step by employing a transformation in NURBS, which we have assisted to use by a large part of the scientific community in cases of complex shapes modelled for objectives that are very different from structural analysis and included in the varied panorama of conservation. Most of the authors mentioned in the first paragraphs (Castellazzi et al. 2015; Barazzetti et al. 2015; Banfi 2017) highlight the need for this choice precisely in the application to the built heritage, mostly historical, compared with the new construction, which determined exactly the need to outline HBIM modelling strategies rather than BIM. It is in fact beyond doubt that most of the examples of the historical architectural heritage are presented as unique cases that require targeted modelling. Furthermore, HBIM modelling information structure appears to be appropriate to account for the timedependent evolution of the strength and stiffness both in case of decrement due to ongoing degradation processes, and in case of improvement thanks to retrofitting interventions. In fact, time can be assumed as an additional model parameter, providing the possibility to trace the different phases of the modelled historical heritage.

\section{Conclusive remarks}

The presented research fulfilled multiple objectives and arose some interesting innovative issues during its development. The priority was given to the investigation of a procedure to 

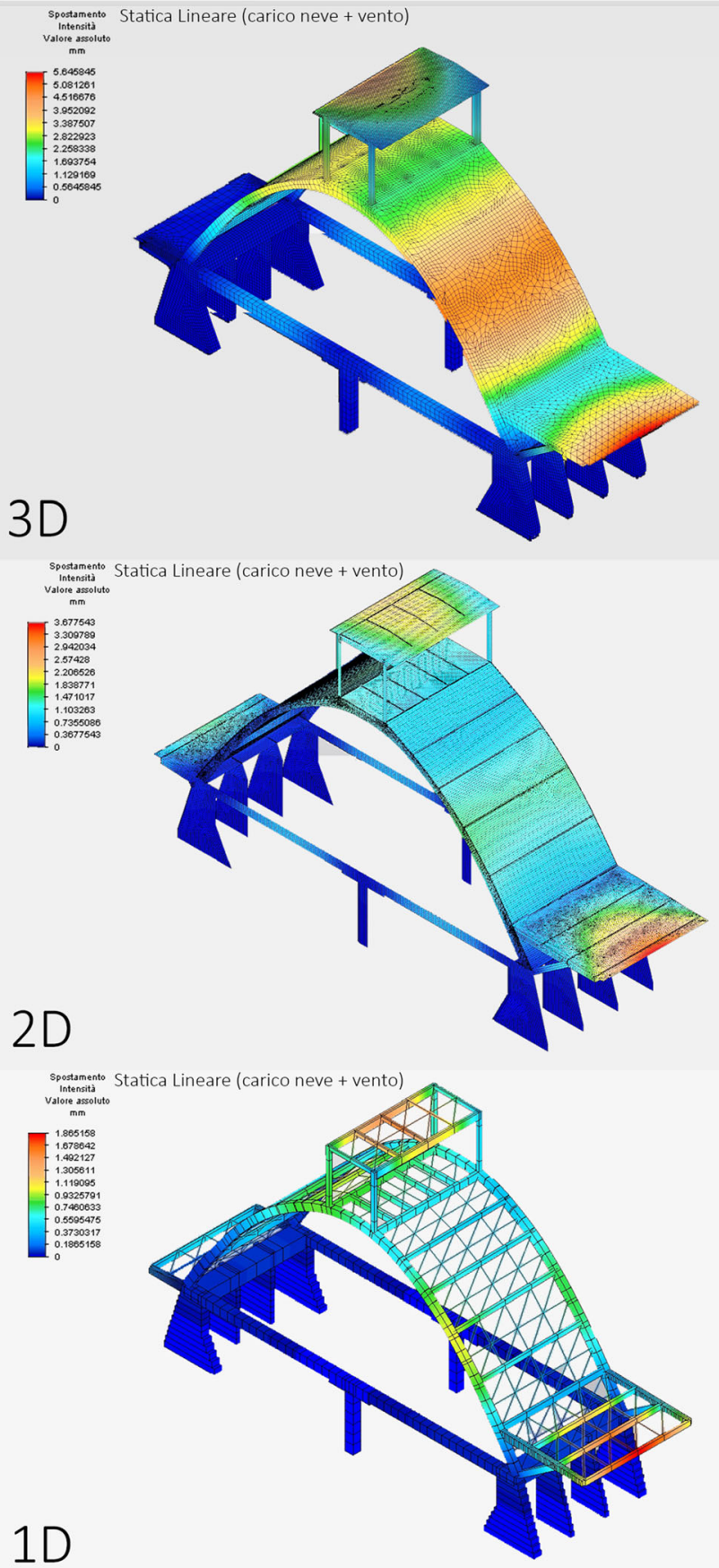

Fig. 15 Displacements under the effect of snow and wind load combination

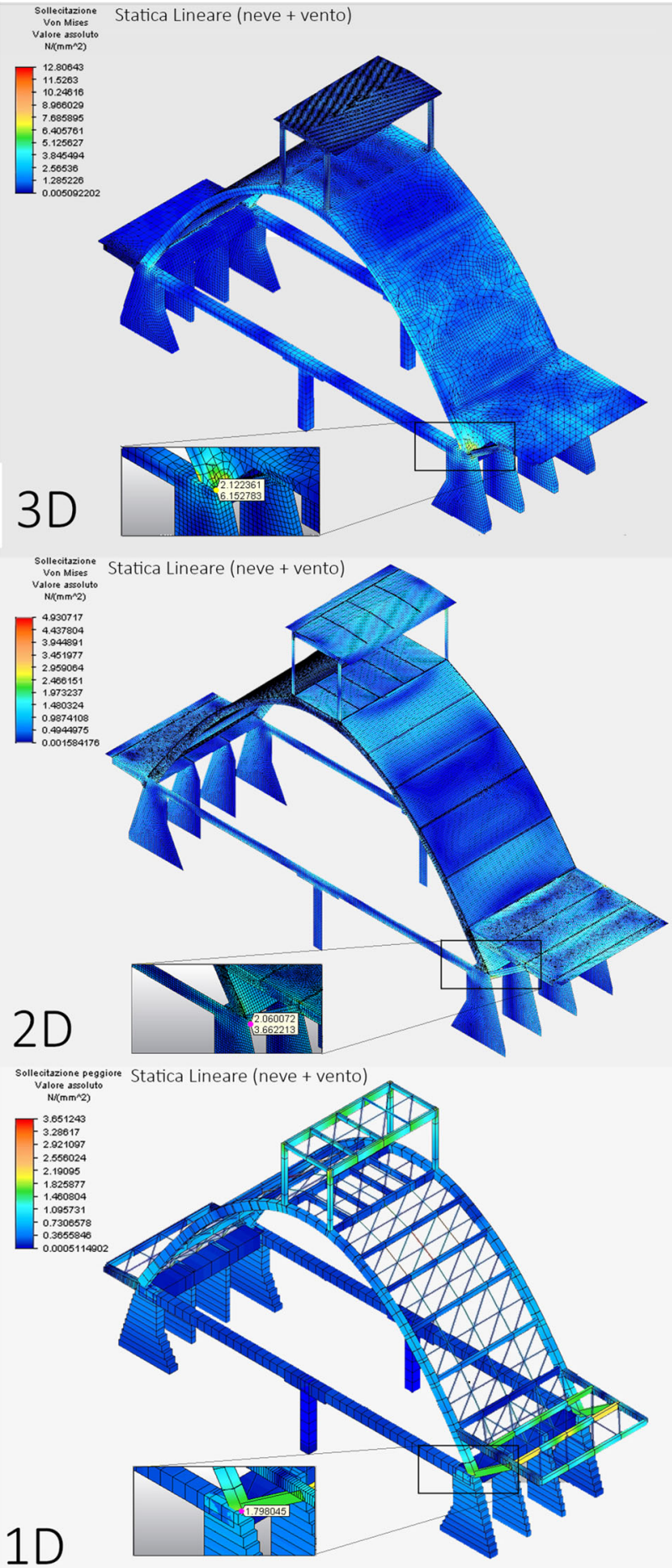

build HBIM models, taking advantage of the as-built strategy and starting from a documentation of investigated object, derived from integrated image- and range-based methods. The procedure is subsequently applied to an extremely unique case study.

The second part of the study compared different approaches for structural analysis by assessing the results of static and dynamic modal analyses. Three different models are considered, from fully $3 \mathrm{D}$ discretization to $2 \mathrm{D}$ and $1 \mathrm{D}$

Fig. 16 Equivalent von Mises stress under the effect of snow and wind load combination

reduced dimension discretization. The computational economy of reduced models is evident. On the other hand, local phenomena require higher dimensional models to be captured correctly. A good balance between the processing times for the structural analysis and the modelling times of the appropriate geometries suggests that the shell configuration of the 


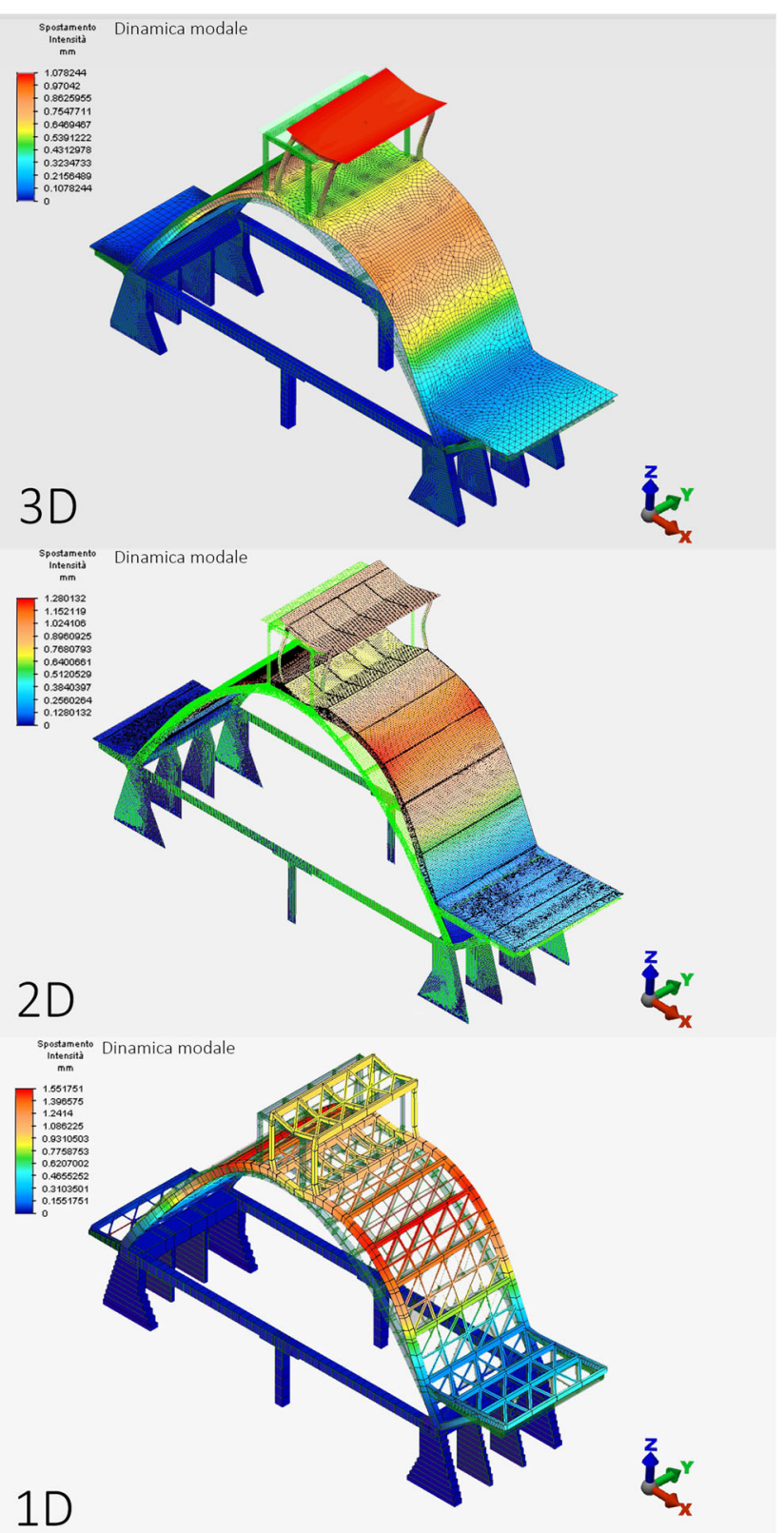

Fig. 17 First modal shape comparison

2D configuration could be the best compromise for the considered case study.

In fact, the parametric nature of the HBIM model comply very well to the actual object, both with respect to the dimensional aspects and to those relating to the structural connections among elements, their materials and construction history. In addition, thanks to encapsulation, the big amount of necessary mechanical parameters can be efficiently stored in a database containing universal parametric structural elements.

HBIM appears to be a leading approach in the field of $\mathrm{CH}$, ranging from abandoned buildings to architectural complex to be recovered or preserved, including the aspect of structural analysis. HBIM optimize interdisciplinary interactions, nowadays widely recognized as a key strategy necessary to interface heterogeneous knowledge.

Sharing a thought by Ottoni et al. (2017), in addition to keeping under observation and testing new methods of managing the huge amount of information that we are certainly able to collect and handle, the simplification processes have to be critically guided in an interdisciplinary sense. They have to be appropriately managed to obtain conceptual, parametric and structural models that are actually able to conduct the appropriate interventions on the built heritage.

Acknowledgements As part of the overall 3D survey of the site using geomatics techniques, carried out by members of the Geomatics laboratory for cultural heritage of the Polytechnic University of Turin, F. Chiabrando oversaw the organization of drone flight, while G. Sammartano oversaw the MMS processing. A special acknowledgement goes to Dr. Consolata Buzzi, President of the Association "Il Cemento nell'identità del Monferrato Casalese", for the attention and help in research activities.

Funding Open access funding provided by Politecnico di Torino within the CRUI-CARE Agreement.

Open Access This article is licensed under a Creative Commons Attribution 4.0 International License, which permits use, sharing, adaptation, distribution and reproduction in any medium or format, as long as you give appropriate credit to the original author(s) and the source, provide a link to the Creative Commons licence, and indicate if changes were made. The images or other third party material in this article are included in the article's Creative Commons licence, unless indicated otherwise in a credit line to the material. If material is not included in the article's Creative Commons licence and your intended use is not permitted by statutory regulation or exceeds the permitted use, you will need to obtain permission directly from the copyright holder. To view a copy of this licence, visit http://creativecommons.org/licenses/by/4.0/.

\section{References}

Abbate E (2016) Sperimentazione per il riconoscimento automatico di elementi parametrici (BIM) da scansioni laser (LIDAR) finalizzata all'analisi agli elementi finiti (FEM). Master thesis, Politecnico di Torino

Acierno M, Cursi S, Simeone D, Fiorani D (2017) Architectural heritage knowledge modelling: an ontology-based framework for conservation process. J Cult Herit 24:124-133

Amadio D (2017) Metodi di rilievo metrico 3D integrati per l'analisi del patrimonio industriale dismesso. Il Caso del Paraboloide di Casale Monferrato. Master thesis, Politecnico di Torino

Banfi F (2017) BIM orientation: grades of generation and information for different type of analysis and management process. Int Arch Photogramm Remote Sens Spat Inf Sci XLII-2/W5

Barazzetti L, Banfi F, Brumana R, Gusmeroli G, Oreni D, Previtali M, Roncoroni F, Schiantarelli G (2015) BIM from laser clouds and finite element analysis: combining structural analysis and geometric complexity. Int Arch Photogramm Remote Sens Spat Inf Sci XL-5/ W4:345-350

Bertolini Cestari C (2011) Il Paraboloide. Un'architettura resistente per forma: la volta sottile di Casale, in Atti e Rassegna Tecnica degli Ingegneri e degli Architetti in Torino, Nuova Serie, 65/2 
Castellazzi G, D’Altri AM, Bitelli G, Selvaggi I, Lambertini A (2015) (2015) from laser scanning to finite element analysis of complex buildings by using a semi-automatic procedure. Sensors 15 : 18360-18380. https://doi.org/10.3390/s150818360

Chiabrando F, Sammartano G, Spanò A (2016) Historical buildings models and their handling via $3 \mathrm{~d}$ survey: from points clouds to user-oriented HBIM. Int Arch Photogramm Remote Sens Spat Inf Sci XLI-B5: 633-640. https://doi.org/10.5194/isprsarchives-XLIB5-633-2016

Chiabrando F, Sammartano G, Spanò A, Spreafico A (2019) Hybrid 3D models: when geomatics innovations meet extensive built heritage complexes. ISPRS Int J Geo-Inf 8:124. https://doi.org/10.3390/ ijgi8030124

ClearEdge3D. Edgewise Building. Available online: http://www. clearedge3D.com/products/ edgewise-building/ (accessed on 30 dec 2019)

Del Giudice M, Osello A (2013) BIM for cultural heritage, in The Int Arch Photogramm Remote Sens Spatial Inform Sci, XL-5/W2, 225229

Diara F, Rinaudo F (2018) Open source HBIM for cultural heritage: a project proposal. Int Arch Photogramm Remote Sens Spat Inf Sci XLII-2:303-309. https://doi.org/10.5194/isprs-archives-XLII-2303-2018

Dore C, Murphy M, McCarthy S, Brechin F, Casidy C, Dirix E (2015) Structural simulations and conservation analysis-historic building information model (HBIM). In: The International Archives of the Photogrammetry, Remote Sensing and Spatial Information Sciences. 3D Virtual Reconstruction and Visualization of Complex Architectures, 25-27 February 2015, Avila

Eyre M, Wetherelt A, Coggan J (2016) Evaluation of automated underground mapping solutions for mining and civil engineering applications. J Appl Remote Sens 10:046011. https://doi.org/10.1117/1. JRS.10.046011

Georgopoulos A, Lambrou E, Pantazis G, Agrafiotis P, Papadaki A, Kotoula L, Lampropoulos K, Delegou E, Apostolopoulou M, Alexakis M, Moropoulou A (2017) Merging geometric documentation with materials characterization and analysis of the history of the holy aedicule in the church of the holy sepulchre in Jerusalem. Int Arch Photogramm Remote Sens Spat Inf Sci XLII-5/W1:487-494. https://doi.org/10.5194/isprs-archives-XLII-5-W1-487-2017

Hrennikoff A (1949) Framework method and its technique for solving plane stress problems. Iabse Publications, Zurigo

Invernizzi S, Spanò A, Chiabrando F (2019) Survey, assessment and conservation of post-industrial cultural heritage: the case of the thin concrete vault in Casale, Italy. In: Aguilar R., Torrealva D., Moreira S., Pando M.A., Ramos L.F. (eds) Structural analysis of historical constructions. RILEM Bookseries, vol 18. Springer, Cham

Kitsaki L (2011) From an industrial memory to a concrete presence: the case of the "Paraboloide" in Casale Monferrato, Master of Conservation of Monuments and Sites, RLICC, Katholieke Universiteit Leuven

Korumaz M, Betti M, Conti A, Tucci G, Bartoli G, Bonora V, Korumaz A, Fiorini F (2017) An integrated terrestrial laser scanner (TLS), deviation analysis (DA) and finite element (FE) approach for health assessment of historical structures. A minaret case study. Eng Struct 153:224-238. https://doi.org/10.1016/j.engstruct.2017.10.026

Leoni C, Ferrarese S, Wahbeh W, Nardinocchi C, (2019) Extraction of main levels of a building from a large point cloud, in The International Archives of the Photogrammetry, Remote Sensing and Spatial Information Sciences, Volume XLII-5/W2

Lo Turco M, Santagati C, Parrinello S, Valenti GM, Inzerillo L (2016) BIM and architectural heritage: towards an operational methodology for the knowledge and the management of cultural heritage, In: Disegnare con, ISSN 1828-5961, 161-169
Logothetis S, Delinasiou A, Stylianidis E (2015) Building information modelling for cultural heritage: a review, in The International Archives of the Photogrammetry, Remote Sensing and Spatial Information Sciences, II-5/W3, 177-183

Lubowiecka I, Armesto J, Arias P, Lorenzo H (2009) Historic bridge modelling using laser scanning, ground penetrating radar and finite element methods in the context of structural dynamics. Eng Struct 31:2667-2676

Luis J, Navarro S, Cabrelles M, Elena A, Haddad N, Akasheh T (2011) Integration of laser scanning and imagery for photorealistic 3D architectural documentation. In Laser scanning, theory and applications; InTech, ISBN 978-953-307-205-0

Munumer E, Lerma JL (2015) Fusion of 3D data from different imagebased and range-based sources for efficient heritage recording. Digital Heritage, Granada, 83-86

Murphy M, McGovern E, Pavia S (2009) Historic building information modelling (HBIM). Struct Surv 27/ 4:311-327

Murphy M, McGovern E, Pavia S (2012) Historic building information modelling -adding intelligence to laser and image based surveys of European classical architecture, In: The International Archives of the Photogrammetry, Remote Sensing and Spatial Information Sciences

Murtiyoso A, Grussenmeyer P, Suwardhi D, Awalludin R (2018) Multiscale and multi-sensor 3D documentation of heritage complexes in urban areas. ISPRS Int J Geo-Inform 7

National Institute Of Building Science, United States. National Building Information Modeling Standard. Version 3-2015. www. nationalbimstandard.org

Ottoni F, Freddi F, Zerbi A (2017) From "models" to "reality", and return. some reflections on the interaction between survey and interpretative methods for built heritage conservation. Int Arch Photogramm Remote Sens Spatial Inf Sci XLII-5/W1, 457-465. https://doi.org/ 10.5194/isprs-archives-XLII-5-W1-457-2017

Quattrini R, Malinverni ES, Clini P, Nespeca R, Orlietti E (2015) From TLS to HBIM. High quality semantically-aware 3D modelling of complex architecture. In: The International Archives of the Photogrammetry, Remote Sensing and Spatial Information Sciences, Volume XL-5/W4

Radicioni F, Matracchi P, Brigante R, Brozzi A, Cecconi M, Stoppini A, Tosi G (2017) The Tempio della Consolazione in Todi: integrated geomatic techniques for a monument description including structural damage evolution in time. Int Arch Photogramm Remote Sens Spat Inf Sci XLII-5/W1:433-440. https://doi.org/10.5194/isprsarchives-XLII-5-W1-433-2017

Sammartano G, Spanò A (2018) Point clouds by SLAM-based mobile mapping systems: accuracy and geometric content validation in multisensor survey and stand-alone acquisition. Appl Geomatics 10:317-339. https://doi.org/10.1007/s12518-018-0221-7

Santarella L (1926) Il cemento armato nelle costruzioni civili ed industriali, Hoepli

Thomson C, Boehm J (2015) Automatic geometry generation from point clouds for BIM. Remote Sens 7:11753-11775. https://doi.org/10. 3390/rs70911753

Volk R, Stengel J, Schultmann F (2014) Review: building information modeling (BIM) for existing buildings - literature review and future needs, automation in construction 38, Elsevier, 109-127

Wang C, Cho Y, and Kim C (2015) Automatic BIM component extraction from point clouds of existing buildings for sustainability applications. In Automation in construction, https://doi.org/10.1016/j. autcon.2015.04.001

Yang X, Lu YC, Murtiyoso A, Koehl M, Grussenmeyer P (2019) HBIM modeling from the surface mesh and its extended capability of knowledge representation. ISPRS Int J Geo-Inf 8:301. https://doi. org/10.3390/ijgi8070301 